\title{
Co-crystals, salts, and ionic co-crystals of ethanol and ammonia
}

\author{
A. Dominic Fortes
}

\section{Published version information}

Citation: AD Fortes. "Co-crystals, salts and ionic co-crystals of ethanol and ammonia." ACS Earth and Space Chemistry (2020).

DOI: $10.1021 /$ acsearthspacechem.0c00155

This document is the unedited author's version of a Submitted Work that was subsequently accepted for publication in ACS Earth and Space Chemistry, (C2020 American Chemical Society, after peer review. To access the final edited and published work see the DOI above.

Please cite only the published version using the reference above. This is the citation assigned by the publisher at the time of issuing the AAM. Please check the publisher's website for any updates. 


\title{
Co-crystals, Salts and Ionic Co-crystals of Ethanol and Ammonia
}

\author{
A. Dominic Fortes, ${ }^{1,2, *}$ \\ ${ }^{1}$ ISIS Neutron \& Muon Spallation Source, Rutherford Appleton Laboratory, Harwell Science \\ and Innovation Campus, Chilton, Oxfordshire, OX11 0QX, United Kingdom. \\ ${ }^{2}$ Department of Earth Sciences, University College London, Gower Street, London WC1E 6BT, \\ United Kingdom. \\ *Corresponding author email: dominic.fortes@stfc.ac.uk
}

\begin{abstract}
Compounds of ethanol and ammonia have been known for over a century but no structural characterisation has been carried out. Solid crystalline specimens of molecular ethanol monoammoniate and ethanol hemi-ammoniate were prepared by flash freezing of stoichiometric liquids in liquid nitrogen followed by annealing between $175 \mathrm{~K}$ and $195 \mathrm{~K}$. High-resolution neutron powder diffraction measurements were used to determine the complete structures of the two compounds. Both are triclinic $(P \overline{1}, Z=2)$ : ethanol mono-ammoniate is characterised by linear tapes of four-sided hydrogen-bonded rings, which extend along the crystal's $b$-axis; ethanol hemiammoniate's structure is defined by sheets (in the crystal's $a-b$ plane) comprised of two different types of four- and six-sided H-bonded rings. Measurements collected as a function of temperature provide a precise determination of the thermal expansion of the two ethanol ammoniates and of solid deutero-ammonia. Density Functional Theory calculations yield insights into the response of each structure to hydrostatic stress, including a proton transfer to form either wholly ionic ammonium ethoxide crystals or ionic co-crystals of ethanol ammonium ethoxide. The switch from molecular to ionic co-crystal in ethanol hemi-ammoniate may occur on cooling at ambient pressure, with kinetic frustration due to the low temperature of the transition.

Proton transfer at ambient pressure, or at modest impact shock pressures, suggests that there may be extensive ammonium salt formation amongst compounds of the simplest alcohols. This may
\end{abstract}


represent an important additional mechanism for the generation of $\mathrm{NH}_{4}{ }^{+}$spectroscopic signatures in remotely sensed data from interstellar, cometary and planetary ices.

Keywords: ethanol, ammonia, co-crystal, neutron diffraction, hydrogen bonds, proton transfer, DFT 


\section{Introduction}

Compounds of alcohols with simple molecules such as water and/or ammonia provide fertile ground for evaluating the competing effects of hydrogen-bond strength on crystal structures and properties. ${ }^{1,2}$ They contain a range of moderately strong $\mathrm{O}-\mathrm{H} \cdots \mathrm{O}$ hydrogen bonds through to weak $\mathrm{C}-\mathrm{H} \cdots \mathrm{O}$ hydrogen bonds. The balance of these interactions may have striking consequences for the overall bulk behaviour, including phenomena such as negative linear compressibility. ${ }^{3}$

Furthermore, these molecules are cosmically abundant; methanol, ethanol and possibly heavier alcohols, form a significant fraction of the mantles of ice grains in star-forming regions, ${ }^{4,5}$ being the most abundant complex organic molecules known in space. ${ }^{6}$ Similarly, ammonia is an abundant component of interstellar ices. ${ }^{7,8}$ These molecules inevitably find their way into the building blocks of planetary systems, the residue of which in our own solar system is a reservoir of comets. Methanol, ethanol, ethylene glycol and even glycoaldehyde have been detected in cometary ices ${ }^{9}$ along with more prevalent water and ammonia. ${ }^{10,11}$ Alternatively, organic molecules such as ethanol, urea and acetic acid may result from hydrothermal processing of molten ices through the rocky cores of icy planetary bodies ${ }^{12}$ that we know to be rich in water and ammonia ices. ${ }^{13,14}$ Consequently, there may be widespread opportunities for simple alcohol hydrates and ammoniates to form in space, on the surfaces or in the interiors of planetary objects. ${ }^{15}$ There is therefore both an intellectual and a practical interest in characterising the structures and physical properties of these compounds.

The solid-liquid equilibria (SLE) in the ethanol-ammonia binary system at atmospheric pressure were reported by Broderson, ${ }^{16}$ from which the existence of several compounds was inferred (Figure 1). These include ethanol hemi- and mono-ammoniates as well as an ammoniarich solid that Broderson determined to be a solid-solution. No evidence of similar solid-solutions is found in any other mixtures of ammonia with small alcohol molecules ${ }^{15,17,18}$ so Broderson's measurements of the ethanol-ammonia binary system, if correct, may have far-reaching implications.

This objective of this work, which forms part of wider study into the crystallography of simple

alcohol - ammonia co-crystals, ${ }^{19-21}$ was to confirm the existence of Broderson's proposed ethanol ammoniates, to determine their crystal structures and both measure and compute various physical properties. Variable-temperature neutron powder-diffraction was the method of choice in carrying 
out the work since it allows for straightforward in situ studies of phase behaviour whilst also providing data required for phase identification and structure solution, including the positions and displacement parameters of the hydrogen atoms. This is particularly important since hydrogen bonds are expected to be the defining structural elements of these types of materials.

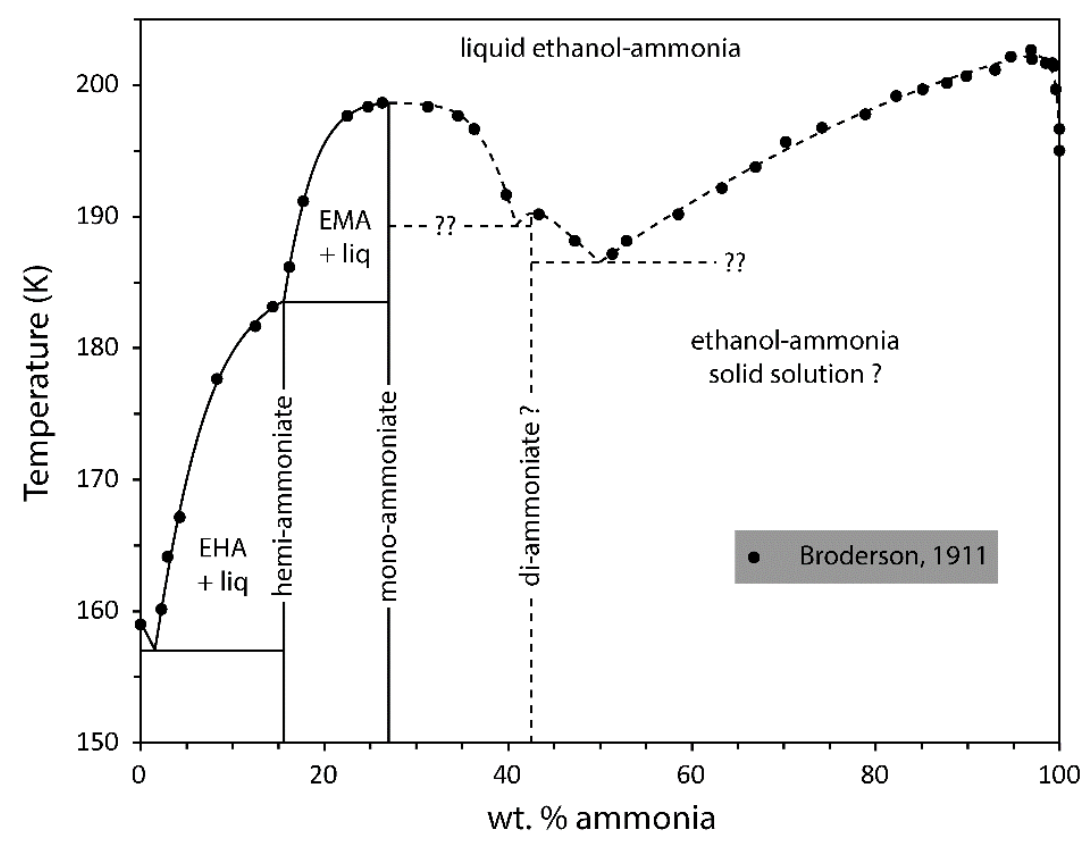

\section{Figure 1}

Ethanol-ammonia binary phase diagram at 1 bar after Broderson. ${ }^{16}$ Dashed lines and the hypothetical ethanol di-ammoniate compound reflect a possible interpretation of the kink in the liquidus curve data around $40 \mathrm{wt}$. \% $\mathrm{NH}_{3}$. The three compositions examined as part of this work are denoted by the vertical solid and dashed lines labelled as hemi-, mono- and di-ammoniate.

\section{Methods}

\section{Experimental methods}

An evacuated glass bulb immersed in a dry-ice-cooled acetone bath ( 220 K) was used to condense liquid deutero-ammonia (Sigma-Aldrich 422975, 99 atom \% D). The condensed ammonia was divided into aliquots that were frozen, weighed and then mixed with appropriate quantities of perdeuterated ethanol (Sigma-Aldrich 186414, 99.5 atom \% D) to form a series of 
stoichiometric solutions. Liquids with three different compositions were prepared: $16.1 \mathrm{wt}$ \% ND 3 in ethanol- $d_{6}$ (ethanol hemi-ammoniate, EHA), 27.8 wt. \% ND3 (ethanol mono-ammoniate, EMA) and 43.5 wt. $\% \mathrm{ND}_{3}$ (ethanol di-ammoniate, EDA). The purpose of the third sample was two-fold: firstly, it allows us to determine if the kink in Broderson's observed liquidus curves ${ }^{16}$ can be explained by the existence of an ethanol di-ammoniate phase; secondly, if no di-ammoniate exists, it allows us to determine if another more ammonia-rich phase exists in the compositional space between EMA and solid ammonia, which may or may not be the proposed solid solution.

The liquid samples were flash frozen by direct immersion in liquid nitrogen. The transparent glassy solids were ground to a fine powder under liquid nitrogen and then transferred into a nitrogen-cooled slab-geometry sample holder composed of 6082-T6 Al-alloy with internal dimensions of $18 \times 23 \mathrm{~mm}$ perpendicular to the beam, and $10 \mathrm{~mm}$ depth parallel to the incident beam. Once filled, the 'back' vanadium foil window of the sample can was attached with screws. Both the 'front' (i.e., beam-facing) and 'back' windows were sealed with $1 \mathrm{~mm}$ indium wire to prevent leakage of material from the interior. The front windows and the body of the sample holder were masked with $\mathrm{Gd}$ and $\mathrm{Cd}$ foil.

Time-of-flight neutron powder diffraction data were collected using the High Resolution Powder Diffractometer (HRPD) at the ISIS Neutron \& Muon Spallation Source (Rutherford Appleton Laboratory, UK). ${ }^{22}$ The bulk of the data collection was done in a neutron time-of-flight (TOF) 'window' between 100 and 200 milliseconds since this places Bragg peaks corresponding with $d$-spacings between 2.2 and $4.0 \AA$ in the instrument's highest-resolution backscattering backs (average $2 \theta=168.33^{\circ}$ ); for hydrogen-bonded molecular 'ices' this tends to be a region where the most intense peaks occur and the separation of lower-order peaks makes indexing of unknown powder patterns quite straightforward. For structure solution and refinement a number of datasets were also measured with the instrument's choppers phased to measure a 30 - $130 \mathrm{~ms}$ time-of-flight window, which captures Bragg peaks between 0.65 and $2.65 \AA$ in the backscattering detectors.

Low temperatures were produced by means of a closed-cycle refrigerator (CCR), equipped with a Sumitomo Heavy Industries Ltd., RDK-415D2 cryo-cooler, mounted in the instrument's sample tank. The normal protocol was to maintain the temperature of the CCR cold head $30-40$ K below the sample temperature whilst using a Watlow Firerod C1E-192 cartridge heater inserted into the frame of the sample holder itself to actively heat and control the sample temperature. The 
sample temperature was measured using a RhFe resistance thermometer (fully-calibrated to ITS1990), also inserted into the body of the sample holder.

All data underwent initial processing using the Mantid suite of powder-diffraction routines, ${ }^{23}$ focussing data in each detector bank to a common scattering angle and then using a $\mathrm{V}: \mathrm{Nb}$ nullscattering standard material to normalise with respect to the spectrum of the incident beam and correct for instrumental efficiency. The output data, in the form of logarithmically-binned histograms, were then analysed by the Rietveld ${ }^{24}$ and LeBail ${ }^{25}$ whole-pattern fitting methods using GSAS/Expgui. ${ }^{26,27}$

Initial examination of the first ethanol mono-ammoniate sample revealed that it was very poorly crystalline, exhibiting weak and broad Bragg peaks. On warming to $180 \mathrm{~K}$, these sharpened and increased substantially in intensity. A structural dataset was obtained in the $30-130 \mathrm{~ms}$ and 100-200 ms time-of-flight windows (counted for $200 \mu \mathrm{A}$ each). ${ }^{a}$ Unfortunately, it was found that part of the gadolinium mask had broken during insertion into the CCR, resulting in the presence of some weak parasitic peaks from aluminium and steel in the diffraction pattern. The sample was recovered under liquid nitrogen and reloaded into another can with an intact Gd mask. This resulted in a slight loss of volatile ammonia and the re-quenched specimen was subsequently found to contain weak accessory peaks from what was later identified as ethanol hemi-ammoniate, EHA. Upon warming from 160 to $180 \mathrm{~K}$, however, the EHA peaks disappeared (most likely because of partial melting) and it was possible to obtain a high-quality structural dataset from phase-pure EMA in the 30-130 ms and 100-200 ms time-of-flight windows counting for 200 and $120 \mu \mathrm{A}$, respectively. Re-cooling led to the reappearance of parasitic EHA peaks between 170 and $160 \mathrm{~K}$.

The quenched EHA composition also required substantial annealing after mounting in the CCR to produce a satisfactory diffraction pattern. Since the peritectic melting point is lower for this composition, caution dictated that warming was stopped at $175 \mathrm{~K}$ and a structural dataset was collected in the 30-130 and 100-200 ms time-of-flight windows (200 $\mu \mathrm{A}$ each). Very small peaks attributable to EMA were identified in these data, indicating that the composition was slightly ammonia-rich. Data were collected on cooling to $~ 70 \mathrm{~K}$ in the 100-200 ms tof window, but there was such a considerable line broadening as the temperature was reduced (Suppl. Fig. S1) that

\footnotetext{
${ }^{a}$ The numbers are integrated proton beam currents, given as a proxy from the measurement duration. HRPD typically measures at a rate of $40 \mu \mathrm{A} \mathrm{hr}^{-1}$, although this depends on a variety of factors, such as synchrotron trips and other losses. Hence the integrated beam current is a more meaningful indication of duration than the real-time length.
} 
continuing further was considered not to be worthwhile. In light of the computational results detailed below, this decision might be construed as being premature.

After quenching and annealing of the di-ammoniate composition at $180 \mathrm{~K}$ it became apparent that the sample consisted of EMA and solid ammonia rather than a distinct crystalline phase of ethanol di-ammoniate or some component of a solid-solution. Profile refinement (see below) indicated that the mixture was 91(1) wt. \% EMA and 9(1) wt. \% solid ammonia. Assuming that the initial stoichiometry was accurate, the phase mixture should be $\sim 78: 22$ rather than 91:9, which suggests that there is another non-crystalline ammonia-rich component present in the mixture. It is possible that not all of the originally glassy material devitrified at $180 \mathrm{~K}$; perhaps additional crystallisation would have occurred on further warming. A structural dataset was collected in the 30-130 and 100-200 ms time-of-flight windows at $180 \mathrm{~K}(200 \mu \mathrm{A}$ each), after which data were collected from the phase mixture on cooling to $10 \mathrm{~K}$ in steps of $10 \mathrm{~K}$ (counting for $20 \mu \mathrm{A}$ each) and whilst there was a degree of line broadening it was not very severe. These data were therefore used to determine the thermal expansion of EMA and solid deutero-ammonia to high precision.

\section{Computational method}

Variable-pressure athermal geometry optimizations of the EHA and EMA structures were done using Density Functional Theory (DFT) and the plane-wave pseudopotential method ${ }^{28,29}$ in order to evaluate details of the intra- and intermolecular geometry, the topology of the electron density and the effect of hydrostatic stress. The calculations were implemented in CASTEP ${ }^{30-32}$ version 17.2 in conjunction with the analysis tools in the Materials Studio software package. Ultrasoft pseudopotentials with basis-set cut-offs of $1200 \mathrm{eV}$ and $\vec{k}$-point grids with reciprocal lattice spacings of $\sim 0.04 \AA^{-1}(6 \times 5 \times 3$ for EMA and $5 \times 4 \times 3$ for EHA) were required to achieve convergence of better than $1 \times 10^{-2} \mathrm{GPa}$ in the stress and better than $1 \times 10^{-3} \mathrm{eV}$ per atom in total energy. The 'PBE' gradient-corrected functional ${ }^{33-34}$ was used in conjunction with the Tkatchenko \& Scheffler (TS) dispersion correction ${ }^{35}$ as this was found to provide accurate results in similar systems. ${ }^{36}$ Structural relaxations were begun from the experimentally-obtained crystal structure using the BFGS method. ${ }^{37}$ These were considered to have converged when the forces on each atom were less than $5 \times 10^{-3} \mathrm{eV}^{-1}$ and each component of the stress tensor was smaller than $0.005 \mathrm{GPa}$.

Post-processing of the DFT calculations was done using C2X, ${ }^{38}$ Vesta $^{39}$ and AIM-UC. ${ }^{40}$ 


\section{Results}

\section{Indexing of the diffraction patterns}

Unlike the two known methanol ammoniates, which are orthorhombic, ${ }^{19,20}$ both of the ethanol ammoniates are triclinic.

The $180 \mathrm{~K}$ powder diffraction data from EMA were indexed using DICVOL06 ${ }^{41}$ with a reduced triclinic cell of dimensions $a=4.0695 \AA, b=5.1759 \AA, c=10.3822 \AA, \alpha=94.861^{\circ}, \beta=$ $94.922^{\circ}, \gamma=97.643^{\circ}$. The figures of merit ${ }^{42,43}$ were $\mathrm{M}(21)=60.1$ and $\mathrm{F}(21)=94.0[0.0060,37]$. Using the molecular volumes of $\mathrm{C}_{2} \mathrm{H}_{5} \mathrm{OH}$ and $\mathrm{ND}_{3}$ in their ambient-pressure crystalline phases, ${ }^{44,45}$ we can obtain an estimate of the unit-cell volume as a function of the number of formula units per unit-cell. The case of $Z=2$ yields $V=216.585 \AA^{3}$, which differs from the indexed unit-cell volume $\left(214.92 \AA^{3}\right)$ by only $0.8 \%$.

The $175 \mathrm{~K}$ powder diffraction data from EHA were similarly indexed with a reduced triclinic cell of dimensions $a=5.4900 \AA, b=7.1120 \AA, c=10.0618 \AA, \alpha=104.389^{\circ}, \beta=100.232^{\circ}, \gamma=$ $96.153^{\circ}$. The figures of merit ${ }^{42,43}$ were $\mathrm{M}(15)=75.1$ and $\mathrm{F}(15)=120.1[0.0045,28]$. As with EMA, the unit-cell volume, $369.74 \AA$, differs by only 1\% from the expected value for $Z=2$ and a 2:1 ratio of ethanol to ammonia using the molecular volumes from the pure crystalline phases.

\section{Structure solution and refinement}

The crystal structures of EMA and EHA were each solved in space-group $P \overline{1}$ using the parallel tempering algorithm implemented in FOX, ${ }^{46,47}$ version 1.6.99. Molecules in the form of Z-matrices were placed randomly in the asymmetric unit and the structure was then optimized against the powder diffraction data over twenty-five runs of 10 million trials. Whilst the ammonia molecules were kept rigid during this process, the ethanol molecules were permitted sufficient flexibility to allow either trans or gauche conformations to occur. The optimizations consistently produced very similar structures with chemically sensible molecular arrangements. The structure with the lowest overall cost function was exported as a CIF file to form the basis for Rietveld refinement with GSAS. 
Structure refinements of both ammoniates were done using HRPD backscattering data measured in both the 30-130 and 100-200 ms time-of-flight windows. Due to the high homologous temperature and the resulting intensity decay to short times, the data below $40 \mathrm{~ms}$ were excluded; one additional artefact just below $60 \mathrm{~ms}$ was also excluded. The resulting model fits are shown in Figure 2 (EMA) and Figure 3 (EHA).

A model of the EMA structure with fully anisotropic atomic displacement parameters (ADPs) yielded $w R_{P}=1.90 \%$ for all 5764 data points and $\chi^{2}=2.157$ for 119 variables. The refinement required inclusion of an absorption parameter and a small degree of preferred orientation $\left(2^{\text {nd }}\right.$ order spherical-harmonic model with a texture index of 1.013).
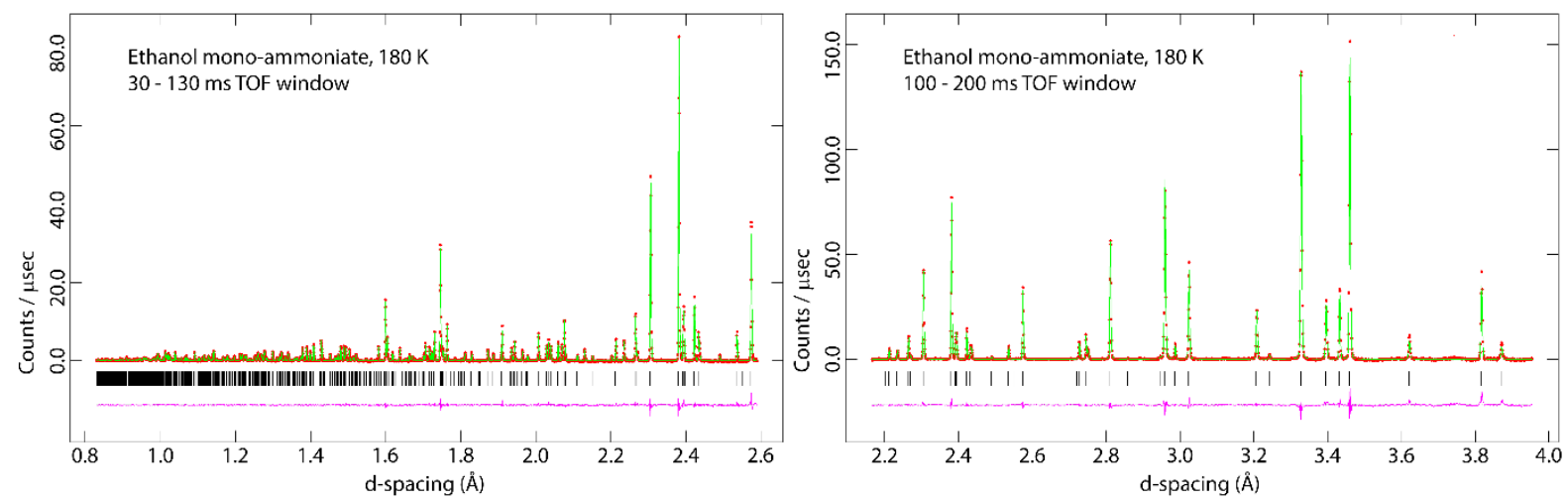

\section{Figure 2}

Background-subtracted neutron powder diffraction pattern of ethanol mono-ammoniate collected at $180 \mathrm{~K}$ in HRPD's $30-130 \mathrm{~ms}$ time-of flight window (left) and the 100-200 ms TOF window (right). Filled red circles show the measured intensities, the green line is a Rietveld model fit and the purple trace underneath the diffraction pattern is the difference profile. Black vertical tick marks show the expected positions of Bragg peaks.

The EHA model structure was similarly refined anisotropically to give $w R_{P}=1.57 \%$ for all 5815 data points and $\chi^{2}=2.459$ for 231 variables. The refinement also required inclusion of an absorption parameter and a small degree of preferred orientation $\left(2^{\text {nd }}\right.$ order spherical-harmonic model with a texture index of 1.019). The structure refinement of EHA reported here was done without EMA being included as an accessory phase. EMA was determined to be present at the level of 1.05(4) wt. \% and the only discernible peaks were in the 100-200 ms time-of-flight 
window, where they were very small and well separated from the peaks of EHA. Refinements done with and without EMA yielded no significant difference in the structural model of EHA, including the ADPs, that was obtained.
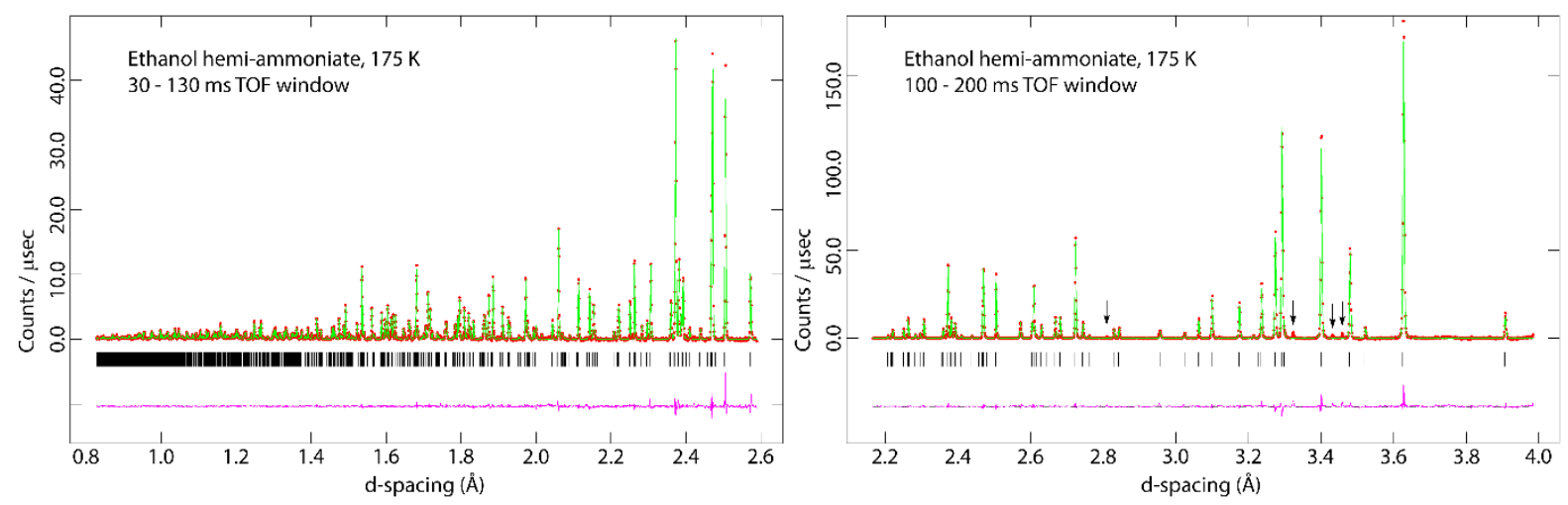

\section{Figure 3}

Background-subtracted neutron powder diffraction pattern of ethanol hemi-ammoniate collected at $175 \mathrm{~K}$ in HRPD's 30-130 ms time-of flight window (left) and the 100-200 ms TOF window (right). Symbols and lines have the same meaning as in Figure 2. Arrows indicate the only visible peaks from EMA in this dataset.

\section{Structures of the ethanol - ammonia co-crystals}

Table 1 reports the internal geometry of the ethanol- $d_{6}$ molecules in both ammoniates compared with the DFT calculations. Atomic coordinates, ADPs $\left(U_{i j}\right)$, equivalent isotropic displacement parameters $\left(U_{i s o}\right)$ and complete tables of bond lengths and angles are provided in Supplementary CIFs. In the $P c$ form of solid ethanol, ${ }^{44}$ one encounters both trans and gauche $e^{-}$conformers of the molecule. Since the asymmetric unit of EMA contains only a single ethanol molecule there can clearly be only one conformer, which is trans. However, in EHA, the ethanol molecule that donates a hydrogen bond to its neighbouring ethanol is gauche ${ }^{-}$and the ethanol molecule that donates a hydrogen bond to ammonia is trans. In all instances, the conformation about the $\mathrm{C}-\mathrm{C}$ backbone is staggered. The DFT calculations produce quite similar $\mathrm{C}-\mathrm{C}$ and $\mathrm{C}-\mathrm{O}$ distances in the ethanol molecules of EMA and both conformations of ethanol in EHA. However, the experimental data 
for the gauche $e^{-}$ethanol molecule in EHA differ significantly from the trans molecule; further data is required to understand the nature and origin of this apparent difference.

\section{Table 1}

Internal geometry of the ethanol molecules in the two ammoniates from the finite-temperature experimental data and from the athermal DFT calculations.

\begin{tabular}{|c|c|c|c|c|c|c|c|c|}
\hline \multicolumn{6}{|c|}{ Ethanol hemi-ammoniate } & \multicolumn{3}{|c|}{ Ethanol mono-ammoniate } \\
\hline $\begin{array}{l}\text { Gauche } \\
\text { molecule }\end{array}$ & Expt. & DFT & Trans molecule & Expt. & DFT & Trans molecule & Expt. & DFT \\
\hline $\mathrm{C} 1-\mathrm{C} 2$ & $1.466(8)$ & 1.5163 & $\mathrm{C} 3-\mathrm{C} 4$ & $1.486(7)$ & 1.5120 & $\mathrm{C} 1-\mathrm{C} 2$ & $1.490(5)$ & 1.5117 \\
\hline $\mathrm{C} 2-\mathrm{O} 1$ & $1.442(8)$ & 1.4385 & $\mathrm{C} 4-\mathrm{O} 2$ & $1.405(6)$ & 1.4361 & $\mathrm{C} 2-\mathrm{O} 1$ & $1.411(4)$ & 1.4276 \\
\hline C1-D4 & $1.092(8)$ & 1.0978 & C3-D10 & $1.069(11)$ & 1.0973 & $\mathrm{C} 1-\mathrm{D} 4$ & $1.060(5)$ & 1.0975 \\
\hline C1-D5 & $1.052(9)$ & 1.0984 & C3-D11 & $1.080(13)$ & 1.0983 & C1-D5 & $1.067(6)$ & 1.0967 \\
\hline C1-D6 & $1.066(10)$ & 1.0965 & C3-D12 & $1.080(7)$ & 1.0968 & $\mathrm{C} 1-\mathrm{D} 6$ & $1.084(5)$ & 1.0964 \\
\hline $\mathrm{C} 2-\mathrm{D} 7$ & $1.041(8)$ & 1.0999 & C4-D13 & $1.059(7)$ & 1.1021 & C2-D7 & $1.099(4)$ & 1.1050 \\
\hline $\mathrm{C} 2-\mathrm{D} 8$ & $1.067(8)$ & 1.1023 & C4-D14 & $1.077(8)$ & 1.1028 & $\mathrm{C} 2-\mathrm{D} 8$ & $1.080(5)$ & 1.1049 \\
\hline O1-D9 & $0.977(7)$ & 1.0182 & O1-D15 & $1.001(7)$ & 1.0425 & O1-D9 & $1.008(4)$ & 1.0317 \\
\hline D4-C1-D5 & $108.0(7)$ & 107.700 & D10-C3-D11 & $108.2(10)$ & 107.951 & D4-C1-D5 & $107.2(4)$ & 108.025 \\
\hline D4-C1-D6 & 106.7(7) & 107.969 & D10-C3-D12 & $112.8(7)$ & 108.591 & D4-C1-D6 & $107.8(4)$ & 107.819 \\
\hline D5-C1-D6 & $111.5(8)$ & 108.487 & D11-C3-D12 & $108.2(7)$ & 107.816 & D5-C1-D6 & 108.4(5) & 108.527 \\
\hline D7-C2-D8 & $104.2(7)$ & 107.036 & D13-C4-D14 & $102.9(6)$ & 106.695 & D7-C2-D8 & $107.8(4)$ & 106.885 \\
\hline D9-O1-C2 & $107.3(5)$ & 108.604 & $\mathrm{D} 15-\mathrm{O} 2-\mathrm{C} 4$ & $107.6(5)$ & 108.177 & D9-O1-C2 & $108.7(3)$ & 108.937 \\
\hline $\mathrm{C} 1-\mathrm{C} 2-\mathrm{O} 1-\mathrm{D} 9$ & $-101.2(6)$ & -101.105 & $\mathrm{C} 3-\mathrm{C} 4-\mathrm{O} 2-\mathrm{D} 15$ & $153.9(5)$ & 154.675 & $\mathrm{C} 1-\mathrm{C} 2-\mathrm{O} 1-\mathrm{D} 9$ & $170.6(3)$ & 170.296 \\
\hline
\end{tabular}

The asymmetric units of the two co-crystals are shown in Figure 4 and Figure 5 . As the measurements on both solids were carried out at high homologous temperatures, the displacement ellipsoids are inevitably very large. 


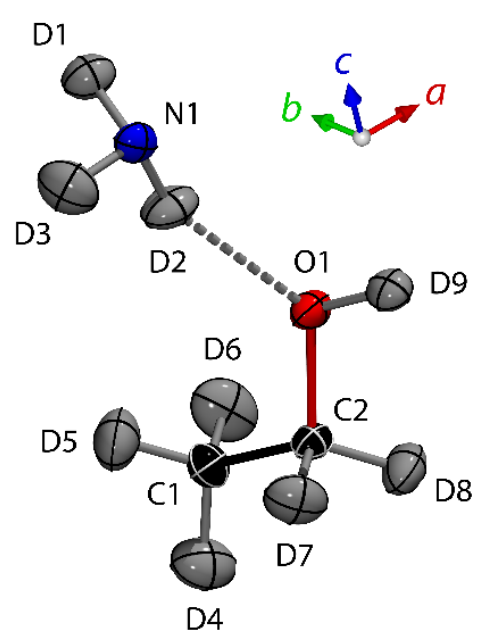

\section{Figure 4}

Asymmetric unit of ethanol mono-ammoniate, indicating the atom labelling scheme used throughout this work. Displacement ellipsoids, due to the high homologous temperature of the measurement and the resultant substantial thermal motion, are drawn at the 25 $\%$ probability level

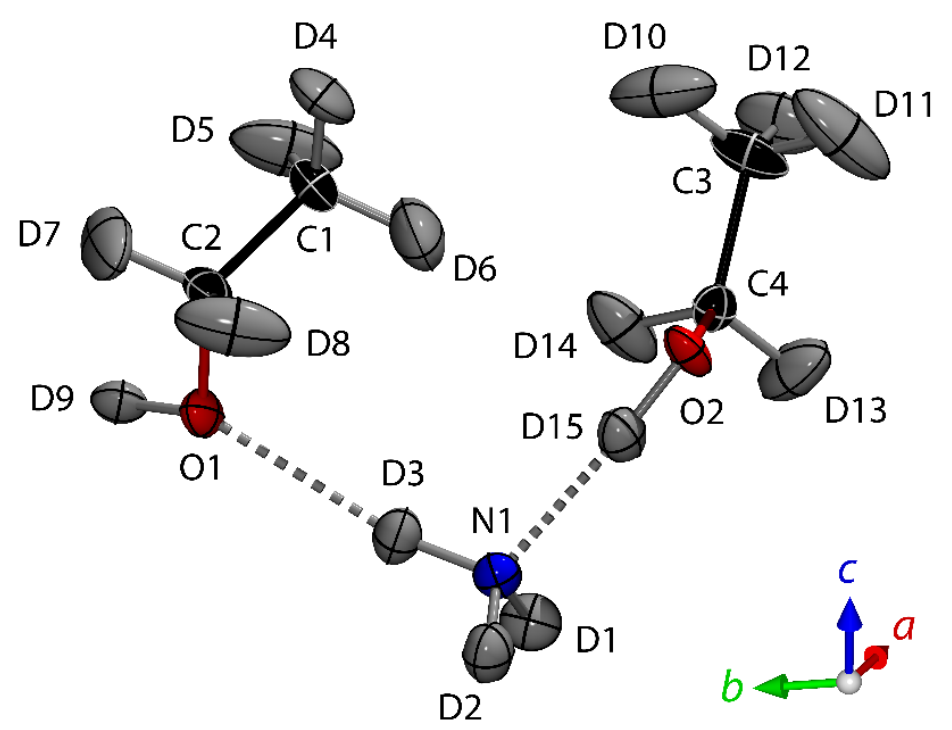

\section{Figure 5}

Asymmetric unit of ethanol hemi-ammoniate, indicating the atom labelling scheme used throughout this work. As in Figure 4, the displacement ellipsoids are drawn at the $25 \%$ probability level.

The arrangement of molecules about inversion centres in EMA leads to the formation of two types of 4-sided hydrogen bonded rings (Figure 6), described in graph-set notation ${ }^{48}$ as $R_{4}^{4}(8)$ and $R_{2}^{2}(8)$. Nearly identical $R_{2}^{2}(8)$ rings are found in the structure of methanol mono-ammoniate. ${ }^{19}$ Both of the 4-sided rings share a common edge and extend as a corrugated tape along the $b$-axis of the crystal. No hydrogen bonding occurs between tapes packed along the $c$-axis; there are no plausible $\mathrm{C}-\mathrm{H} \cdots \mathrm{O}$ or $\mathrm{C}-\mathrm{H} \cdots \mathrm{N}$ contacts in the crystal at all, and the interactions are of a purely 
van der Waals nature. Packing of the tapes along the $a$-axis is more interesting; the D3 deuterons of the ammonia molecule point alternately 'up' and 'down' along the $a$-axis at opposing corners of the four-sided rings. The contact to ammonia in the adjacent tapes is thus quite linear (N-D3 $\cdots \mathrm{N}$ $\approx 168^{\circ}$ ) but very long $(\mathrm{N} \cdots \mathrm{N} \approx 4.07 \AA$ ), so could not reasonably described as a weak hydrogen bond, despite the obvious linearity. The ethanol $\mathrm{O} 1$ atoms in the adjacent tapes are slightly closer $\left(\mathrm{N} \cdots \mathrm{O} \approx 3.63 \AA\right.$ ) but the contact is very far from linear $\left(\mathrm{N}-\mathrm{D} 3 \cdots \mathrm{O} 1 \approx 135^{\circ}\right)$ although it should be noted that similar departures from $\mathrm{H}$-bond linearity occur in solid ammonia. ${ }^{45}$ The $\mathrm{D} \cdots \mathrm{O}$ distance remains substantially longer than the van der Waals radii sum $(2.64 \AA)^{49}$ so this contact also cannot be categorised as a hydrogen bond. Geometric parameters of the hydrogen bonds in EMA are given in Table 2.
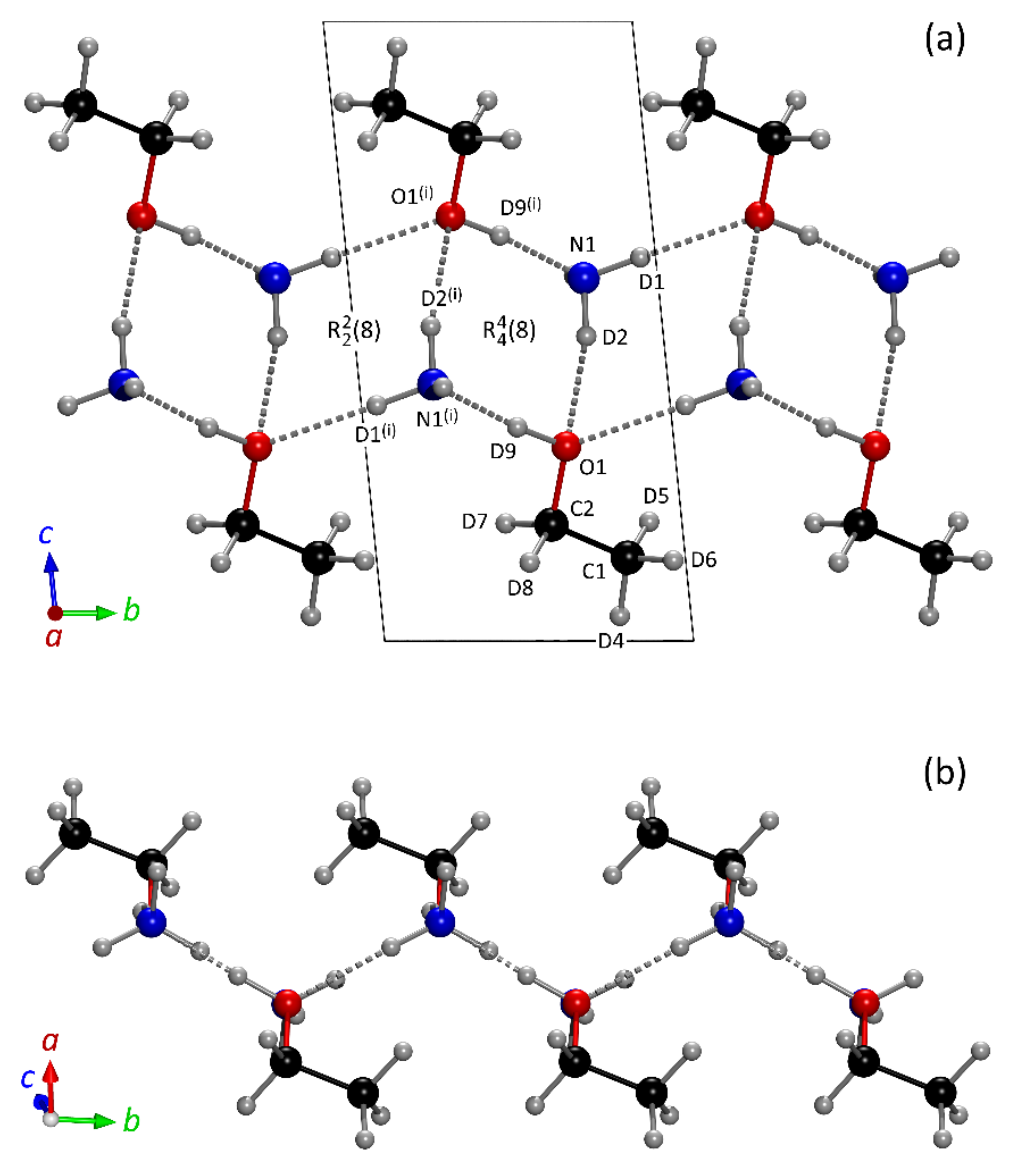

\section{Figure 6}

(a) Illustration of the hydrogen bonding network in ethanol mono-ammoniate, arranged into tapes of edge-sharing 4-sided rings along the $b$-axis. (b) The corrugation of these tapes, viewed along the $\mathrm{N} \cdots \mathrm{O}$ 'creases'. Symmetry codes: (i) $2-x, 1-y, 1-z$. 


\section{Table 2}

Experimentally-determined geometry of the hydrogen bonds in ethanol mono-ammoniate.

\begin{tabular}{|l|c|c|c|c|}
\hline & $\mathrm{D}-\mathrm{H}(\AA)$ & $\mathrm{H} \cdots \mathrm{A}(\AA)$ & $\mathrm{D} \cdots \mathrm{A}(\AA)$ & $\mathrm{D}-\mathrm{H} \cdots \mathrm{A}\left({ }^{\circ}\right)$ \\
\hline $\mathrm{O} 1-\mathrm{D} 9 \cdots \mathrm{N} 1^{(\mathrm{i})}$ & $1.008(4)$ & $1.796(4)$ & $2.801(4)$ & $175.1(3)$ \\
\hline $\mathrm{N} 1-\mathrm{D} 1 \cdots \mathrm{O} 1^{(\text {ii) }}$ & $1.005(4)$ & $2.169(4)$ & $3.170(4)$ & $174.6(3)$ \\
\hline $\mathrm{N} 1-\mathrm{D} 2 \cdots \mathrm{O} 1$ & $1.001(4)$ & $2.198(5)$ & $3.150(4)$ & $158.5(3)$ \\
\hline $\mathrm{N} 1-\mathrm{D} 3 \cdots \mathrm{O} 1^{\text {(iii) }}$ & $1.007(5)$ & $2.844(5)$ & $3.629(4)$ & $135.3(3)$ \\
\hline & & & & \\
\hline
\end{tabular}

(i) $2-x, 1-y, 1-z$ : (ii) $2-x, 2-y, 1-z$ : (iii) $1-x, 1-y, 1-z$.

Analysis of the electron density from DFT calculations provides some insight into the very long and weak inter-layer contacts. Figure 7 depicts a section of the electron density containing the long $\mathrm{D} 3 \cdots \mathrm{O} 1$ and D3 $\cdots \mathrm{N} 1$ contacts. Clearly, there is both a greater electron density, as well as a topological saddle point, along the D3 $\cdots \mathrm{O} 1$ vector. Whilst evidence has been presented that such features are not necessarily indicative of a chemical bond $d^{50,51}$ and that the use of terms such 'bond critical points' is unwarranted, ${ }^{52}$ the excellent summary of this debate by Taylor ${ }^{53}$ does allow us to propose that the stronger of the two interactions is likely to be the most competitive. Hence it should not be surprising that the weak D3 $\cdots \mathrm{O} 1$ interaction is a particularly relevant aspect of the structure's response to both temperature and pressure, as detailed the sections below.

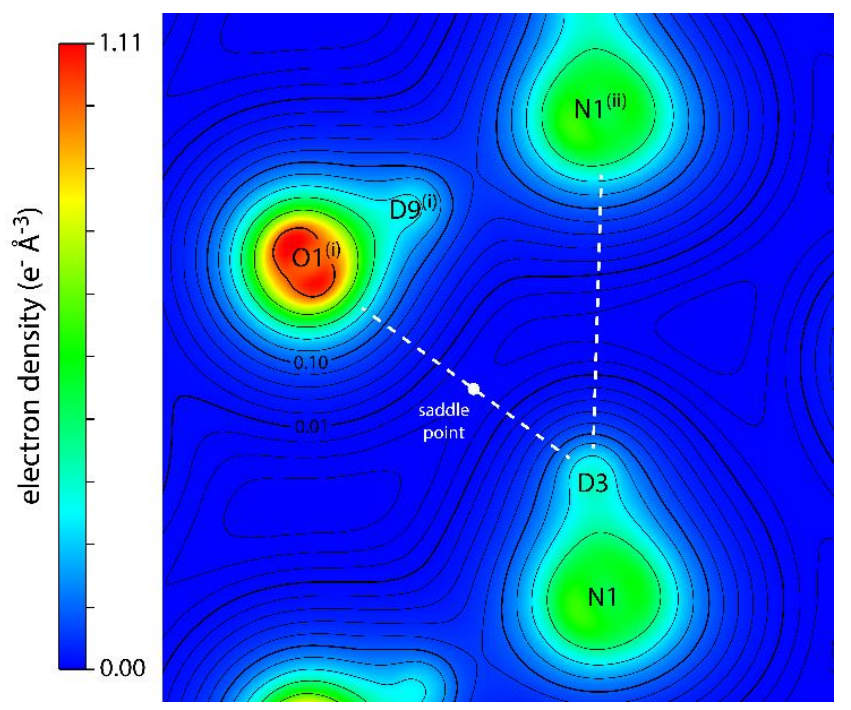

\section{Figure 7}

DFT-calculated electron density in a place defined by $\mathrm{D} 3, \mathrm{O} 1^{(\mathrm{i})}$ and $\mathrm{N} 1^{(\mathrm{ii})}$ revealing the presence of a saddle point between D3 and $\mathrm{O} 1^{(\mathrm{i})}$. The dashed white line between D3 and $\mathrm{O} 1$ represents the 
interaction which develops into a full hydrogen bond under compression (Figure 13a). N.B. Contour lines are in logarithmic intervals. Symmetry codes: (i) $1-x, 1-y, 1-z$; (ii) $x-1, y, z$.

The structure of EHA contains similar motifs to EMA, built around inversion centres. The same $R_{2}^{2}$ (8) rings occur, but the adjoining rings have the second ethanol molecule inserted so as to convert them from four-sided $R_{4}^{4}(8)$ rings into six-sided $R_{6}^{6}(12)$ rings (Figure 8). These extend as infinite tapes along the $b$-axis of the crystal. In EHA, however, there is further hydrogen bonding along the $a$-axis to form a second $R_{2}^{2}(8)$ ring (involving D2 and D3 instead of D1 and D3) and a second $R_{6}^{6}(12)$ ring (Figure 9). The two hexagonal rings differ in their geometry, one adopting a chair conformation and the other being planar. This network of 4- and 6-sided rings forms an infinite sheet in the $a-b$ plane. There are two plausible candidate $\mathrm{C}-\mathrm{H} \cdots \mathrm{O}$ hydrogen bonds, based on the literature definitions of length, ${ }^{54}$ linearity ${ }^{55}$ and electron density ${ }^{56}$ for such interactions linking ethanol molecules within each sheet (Table 3). No hydrogen bonding occurs between the layers and, as in EMA, I conclude that the interactions along $c$ are purely dispersive.

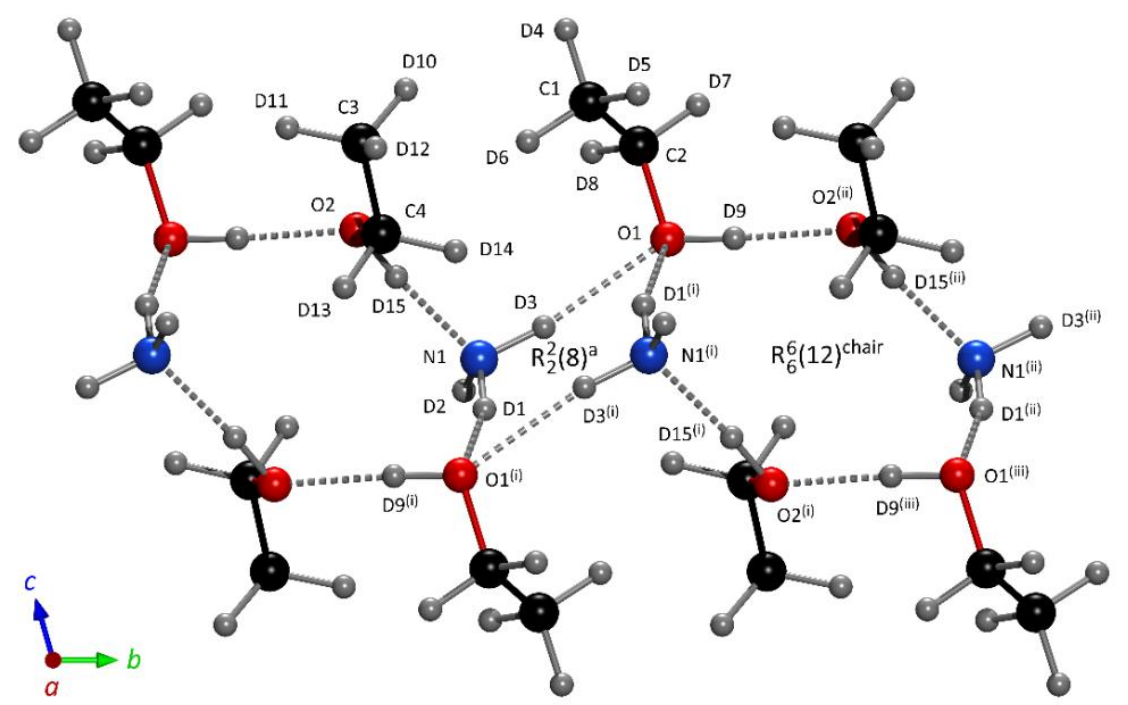

\section{Figure 8}

Illustration of part of the hydrogen bonding network in ethanol hemi-ammoniate showing the arrangement of $(\mathrm{C}-\mathrm{H})_{n}$ groups about the sheet of 4- and 6-sided rings. Symmetry codes: (i) 1-x, $1-y,-z$; (ii) $x, 1+y, z$; (iii) $1-x, 2-y,-z$. 


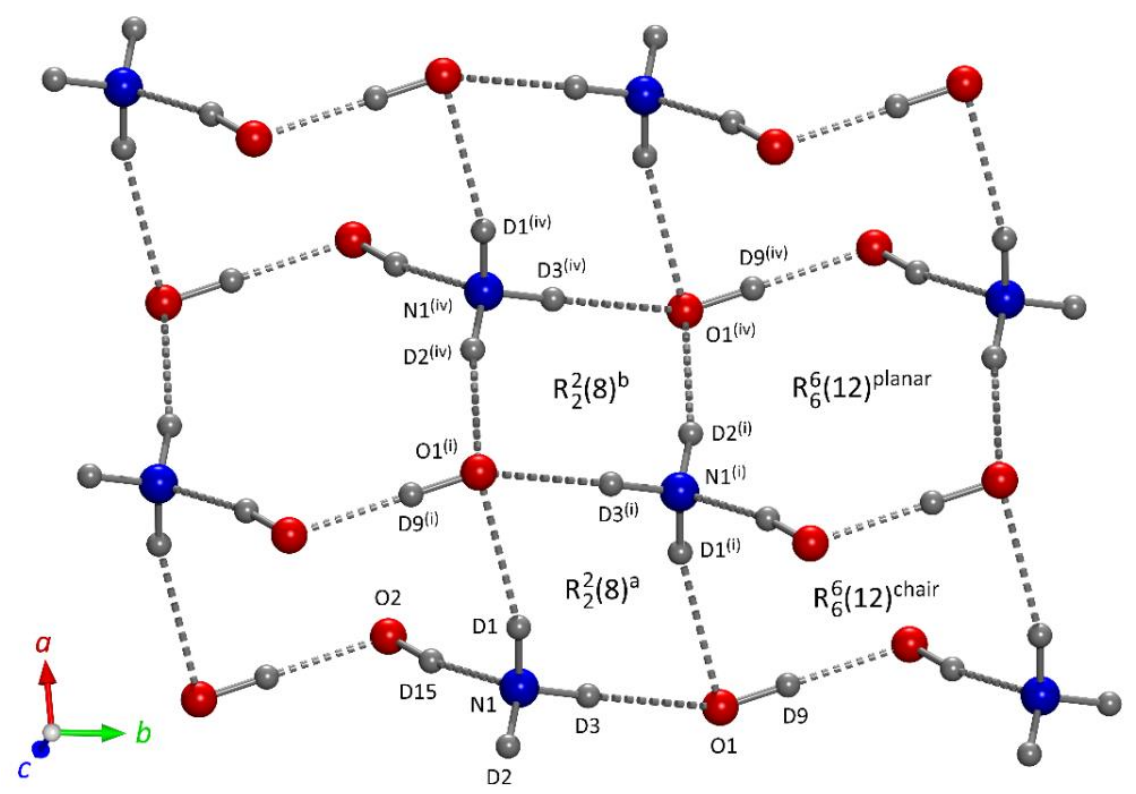

\section{Figure 9}

Wider view of the hydrogen bonding network in ethanol hemi-ammoniate with the $(\mathrm{C}-\mathrm{H})_{n}$ groups omitted for clarity. Symmetry codes: (i) $1-x, 1-y,-z$; (iv) $1+x, y, z$.

\section{Table 3}

Experimentally-determined geometry of the hydrogen bonds in ethanol hemi-ammoniate.

\begin{tabular}{|l|c|c|c|c|}
\hline & $\mathrm{D}-\mathrm{H}(\AA)$ & $\mathrm{H} \cdots \mathrm{A}(\AA)$ & $\mathrm{D} \cdots \mathrm{A}(\AA)$ & $\mathrm{D}-\mathrm{H} \cdots \mathrm{A}\left({ }^{\circ}\right)$ \\
\hline $\mathrm{O} 1-\mathrm{D} 9 \cdots \mathrm{O} 2^{(\mathrm{i})}$ & $0.979(7)$ & $1.747(7)$ & $2.725(7)$ & $177.5(6)$ \\
\hline $\mathrm{N}-\mathrm{D} 1 \cdots \mathrm{O} 1^{\text {(ii) }}$ & $1.011(6)$ & $2.294(7)$ & $3.239(6)$ & $155.0(4)$ \\
\hline $\mathrm{N}-\mathrm{D} 2 \cdots \mathrm{O} 1^{\text {(iii) }}$ & $0.997(5)$ & $2.203(6)$ & $3.184(5)$ & $167.9(5)$ \\
\hline $\mathrm{N}-\mathrm{D} 3 \cdots \mathrm{O} 1$ & $1.020(6)$ & $2.177(6)$ & $3.184(6)$ & $169.1(5)$ \\
\hline $\mathrm{O} 2-\mathrm{D} 15 \cdots \mathrm{N}$ & $0.997(7)$ & $1.785(7)$ & $2.775(7)$ & $171.7(5)$ \\
\hline $\mathrm{C} 1-\mathrm{D} 6 \cdots \mathrm{O} 2$ & $1.069(10)$ & $2.783(9)$ & $3.844(7)$ & $171.8(7)$ \\
\hline $\mathrm{C} 3-\mathrm{D} 12 \cdots \mathrm{O} 2^{\text {(iv) }}$ & $1.086(7)$ & $2.659(7)$ & $3.661(7)$ & $153.3(4)$ \\
\hline & & & & \\
\hline
\end{tabular}

(i) $x, 1+y, z$ : (ii) $1-x, 1-y,-z$ : (iii) $-x, 1-y,-z$ : (iv) $1+x, y, z$. 


\section{Thermal expansion of the ethanol - ammonia co-crystals}

The unit-cell parameters of EMA as a function of temperature $(10-180 \mathrm{~K})$ are given in Suppl. Table S1 and plotted in Suppl. Fig. S2. Those of EHA (70 - 175 K) are provided in Suppl. Table S2 and Suppl. Fig. S3. In both compounds, precision at low temperatures is poorer due to broadening of the Bragg peaks, although the effect is more pronounced in the hemi-ammoniate.

In order to interpolate smoothly between these data and obtain some insight into the underlying vibrational characteristics of the material, the lattice parameters of EMA have been fitted with a second-order Grüneisen approximation to the zero-pressure equation of state (Eq. 1). In this approximation, the thermal expansion is considered equivalent to elastic strain such that,

$$
V(T)=V_{0}\left[1+\frac{E(T)}{Q-b E(T)}\right]
$$

where $V_{0}$ is the unit cell volume at zero pressure, $b=1 / 2\left(K_{0}^{\prime}-1\right)$ and $Q=\left(V_{0} K_{0} / \gamma\right) ; K_{0}$ is the zero pressure isothermal bulk modulus, $K_{0}^{\prime}$ is its first derivative with respect to pressure, and $\gamma$ is the thermal Grüneisen parameter. The internal energy due to lattice vibrations, $E(T)$, is then determined via a Debye model:

$$
E(T)=\frac{9 n k_{B} T}{\left(\theta_{D} / T\right)^{3}} \int_{0}^{\theta_{D} / T} \frac{x^{3}}{e^{x}-1} d x
$$

where $\theta_{\mathrm{D}}$ is the Debye temperature, $n$ is the number of atoms per formula unit, and $\mathrm{k}_{\mathrm{B}}$ is the Boltzmann constant; the integral term is evaluated numerically.

So as to be dimensionally correct, the lengths of the unit-cell edges were fitted as $a^{3}, b^{3}$ and $c^{3}$. The values of $K_{0} / \gamma$ reported for each axis therefore correspond with, e.g., $K_{a} / \gamma=-a^{3}\left(\mathrm{~d} P / \mathrm{d} a^{3}\right)$. The inter-axial angles often exhibit behaviour that is not readily described by models such as Eq. 1 ; consequently these have been fitted with polynomials, with due consideration to the temperature derivatives being zero at $0 \mathrm{~K}$ (i.e., no linear terms in $T$ ) as well as the statistical significance of the coefficients. The fit parameters are given in Supplementary Table S3. Since the measurements on EHA were truncated at $70 \mathrm{~K}$, and we therefore lack the regions of saturation that constrain 
quantities such as the Debye temperature, the EHA lattice parameters have been fitted with simple $3^{\text {rd }}$ and $4^{\text {th }}$ order polynomials. These should thus be treated as nothing more than a guide to the eye and of no predictive value outside of the fitted range.

Whilst substantial anisotropy is expected from the reduced dimensionality of the H-bond networks, an accurate representation of the thermal expansion for a triclinic crystal requires determination of the strain tensor, its eigenvalues and eigenvectors. These are, respectively, the magnitudes and directions of the principal directions of the thermal expansion tensor, denoted $\alpha_{1}$, $\alpha_{2}$ and $\alpha_{3}$. Strain tensors between consecutive pairs of lattice parameters were found, ${ }^{57,58}$ from which the values of the principal and volumetric thermal expansion coefficients were obtained by standard matrix decomposition methods.

Figure 10 reports the principal linear expansivities and the volume thermal expansion coefficients of EMA and EHA derived using the methods outlined above. The values of $\alpha \mathrm{v}$ at high homologous temperatures, $5-6 \times 10^{-4} \mathrm{~K}^{-1}$, are comparable with other simple alcohol hydrate crystals ${ }^{3,36}$ but $\sim 50 \%$ greater than that found in methanol mono-ammoniate. ${ }^{59}$ It is interesting to note the dramatic change in the thermal expansion of EHA above $\sim 130 \mathrm{~K}$, where both $\alpha_{1}$ and $\alpha_{2}$ increase sharply and $\alpha_{3}$ turns negative. This temperature also corresponds with the onset of substantial size and strain broadening of the Bragg peaks on cooling ( $c f$., Suppl. Fig. S1).

In a triclinic crystal, there are no symmetry restrictions on the orientation of the principal directions, and so these do not typically correspond with the crystallographic axes. In lieu of a long table of direction cosine matrices, and since the orientations of the principal directions do not change substantially with temperature, the most expedient way to understand the directionality of the thermal expansion is from Figure 11. This shows the tensor representation surface ${ }^{60,61}$ viewed along the direction of least thermal expansion, $\alpha_{3}$, in relation to the unit-cell edges at $175 \mathrm{~K}$. For EMA, the structural relationship is very clear; the largest thermal expansion, $\alpha_{1}$, corresponds closely with the weak $\mathrm{N} 1 \cdots \mathrm{O} 1$ interaction between the corrugated tapes of 4 -sided rings. For EHA, however, the relationship is more obscure. The direction of greatest thermal expansion is canted with respect to planes of $\mathrm{H}$-bonded sheets whilst the direction of negative expansion is approximately aligned with the $\mathrm{C} 1-\mathrm{C} 2$ bond. It may be the case that increasing the interlayer separation on heating permits adjustment of the in-sheet geometry such that the $\mathrm{C} 1$ methyl groups interlock more efficiently, contracting the lattice planes perpendicular to $\alpha_{3}$. A variabletemperature single-crystal study is required in order to verify this hypothesis. 

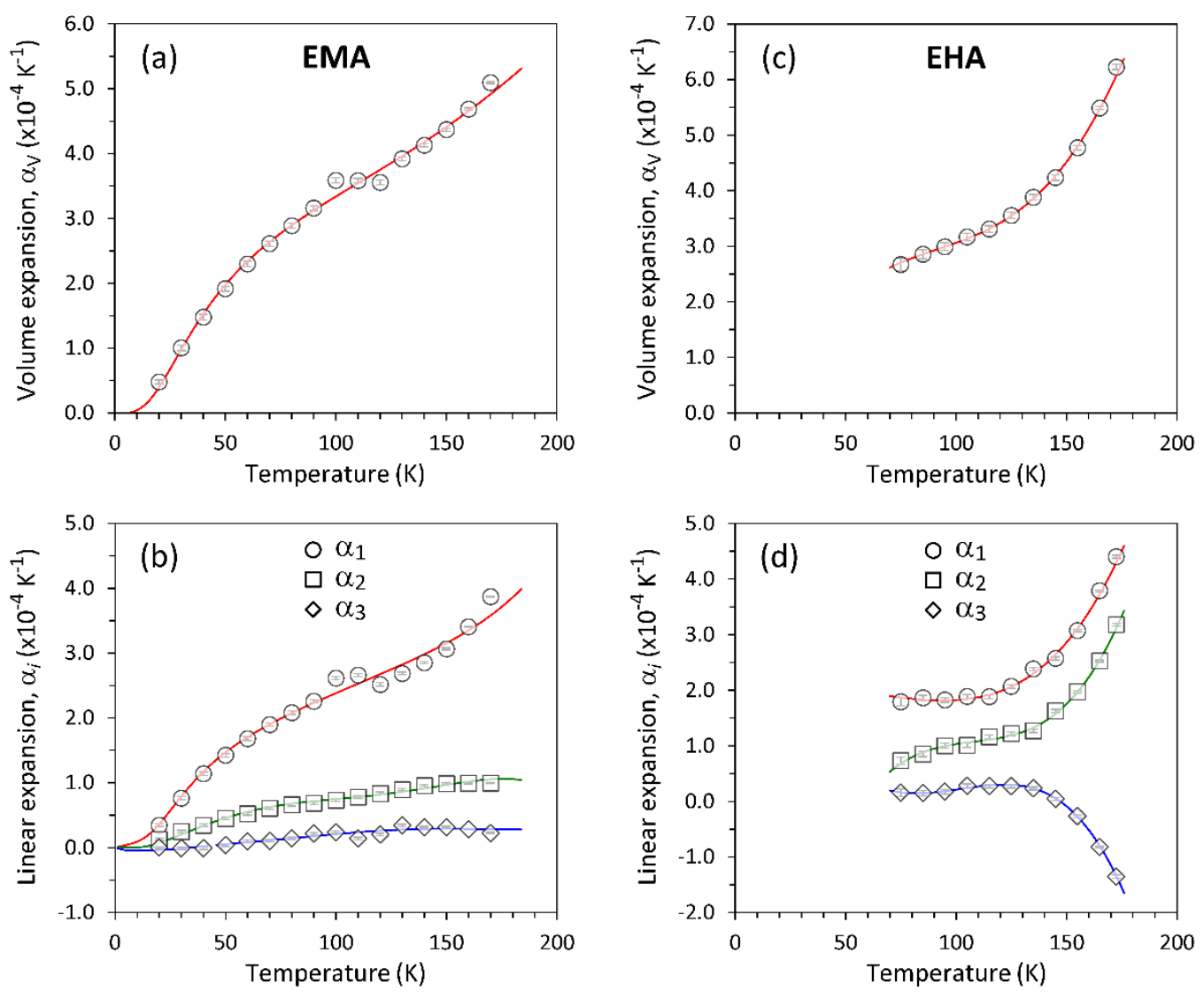

\section{Figure 10}

Thermal expansion coefficients: (a) volume expansion and (b) principal linear expansivities of ethanol mono-ammoniate. For the orientation of the principal directions, refer to Figure 11. Symbols represent point-by-point derivatives of the refined unit-cell parameters and solid lines are derived from the fitted models described in the text. The equivalent results for ethanol hemiammoniate are shown in (c) and (d). 

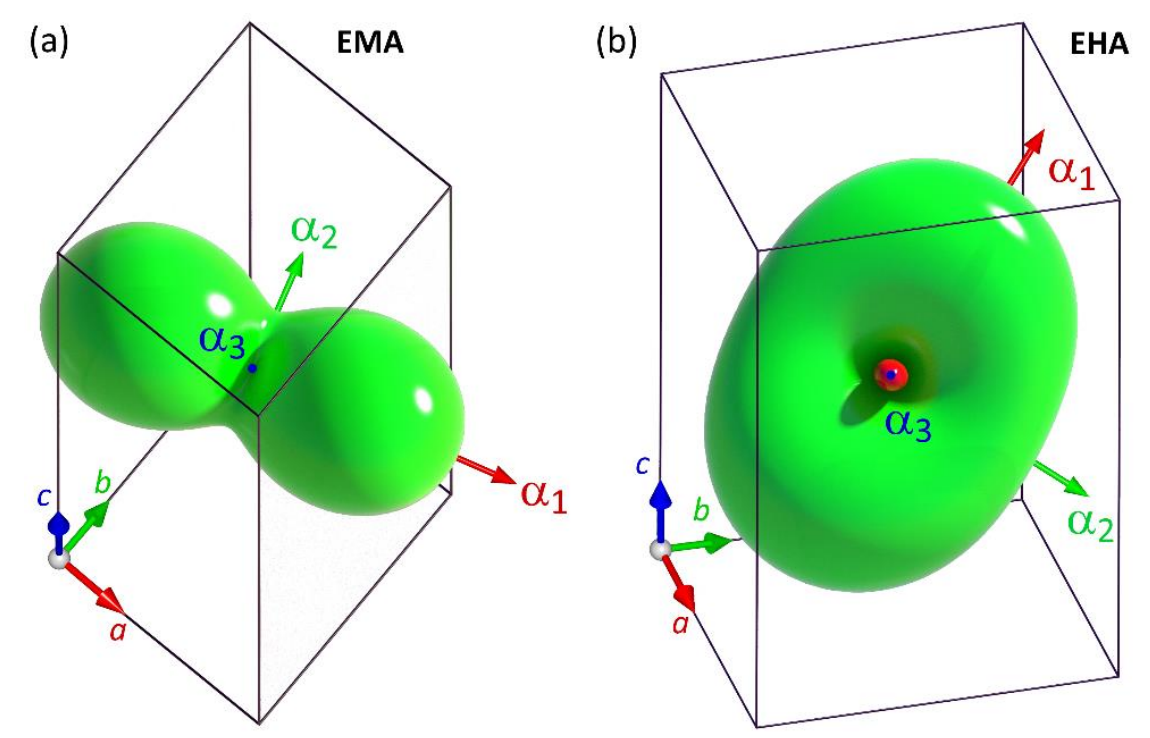

\section{Figure 11}

Thermal expansion tensor representation surfaces for ethanol mono-ammoniate (a) and ethanol hemi-ammoniate (b), each evaluated at $175 \mathrm{~K}$ and drawn parallel with the direction $\alpha_{3}$. The disposition of the unit-cell edges and the two perpendicular principal directions, $\alpha_{1}$ and $\alpha_{2}$, are indicated. Green surfaces show positive expansivity and red surfaces show negative expansivity.

\section{Thermal expansion of solid ammonia}

For the purpose of confirming that the cubic crystal co-existing with EMA in the so-called EDA sample is pure solid ammonia rather than some solid solution, as proposed by Broderson, ${ }^{16}$ it is useful to analyse the lattice parameters and thermal expansion of this phase. The temperature dependence of the cubic lattice parameter is given in Suppl. Table S4 and plotted in Fig. 12a. Clearly, these data are in excellent agreement with literature data for $\mathrm{ND}_{3}$ reported by Olovsson \& Templeton ${ }^{62}$ and differ from Hewat $\&$ Riekel $^{45}$ by only $0.2 \%$. It therefore seems highly likely that this phase is pure ammonia. 

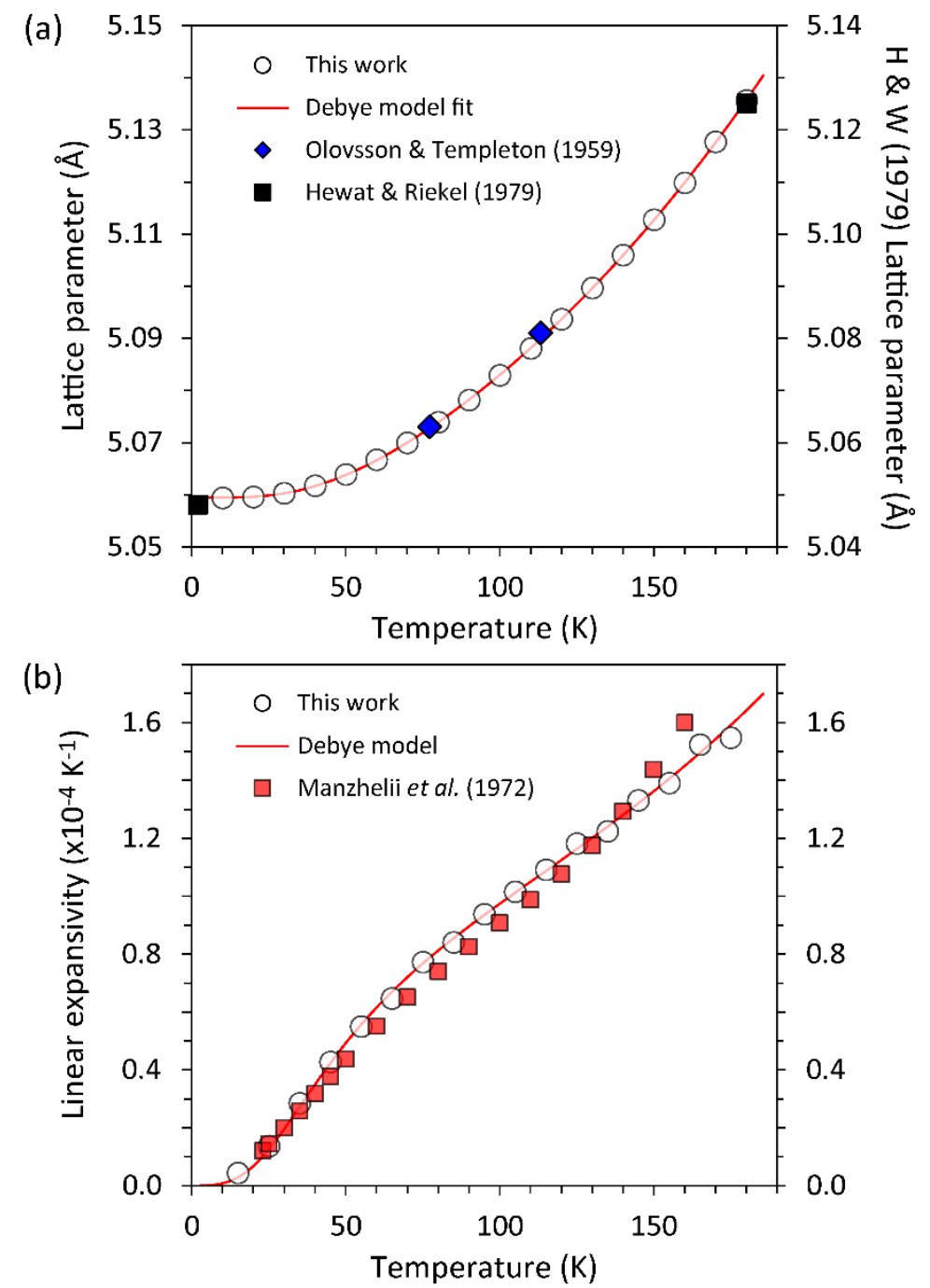

\section{Figure 12}

Lattice parameter (a) and linear thermal expansion (b) of solid ammonia obtained in this work and compared with literature data.

The linear expansion coefficients of solid ammonia, $\mathrm{NH}_{3}$ and $\mathrm{ND}_{3}$, have been reported previously in the range $23-180 \mathrm{~K}$ from dilatometry measurements. ${ }^{63,64}$ From examination of that work it is not clear how well the sample was thermally equilibrated as the temperature was varied and whether there may have been substantial inhomogeneities in temperature through the sample. Furthermore, there is no obvious correction for sublimation at high homologous temperatures, which can have a measurable effect on the physical dimensions of small volatile samples. As noted 
earlier, my thermal protocol pays particular attention to thermal equilibration and precise control during each measurement; moreover, sublimation is of no relevance due to the nature of the bulk crystallographic probe. Nevertheless, there is good agreement between my derived linear expansion coefficient, $\alpha_{\mathrm{L}}$, for solid deutero-ammonia and those of Manzhelii et al. ${ }^{64}$ (Fig. 12b).

These data were fitted with the $2^{\text {nd }}$ order Debye model (Eqs. 1 and 2) to produce the solid lines in Figure 12. The resulting fit parameters are: $V_{0}=19.4981(5) \mathrm{cm}^{3} \mathrm{~mol}^{-1} ; \theta_{\mathrm{D}}=206(2) \mathrm{K} ; K_{0} / \gamma=$ 17.5(2) $\mathrm{GPa} ; K_{0}^{\prime}=17.1(4)$. The Debye temperature is in reasonable agreement with values of $\sim 220$ K obtained from the low-temperature heat capacity ${ }^{64}$ and from ultrasonic measurements. ${ }^{65}$ The incompressibility of solid ammonia has been determined experimentally $65-67$ and computationally, ${ }^{68}$ yielding values in the range of $5-6 \mathrm{GPa}$. Since $\gamma$ is known to be $\sim 1.3$ at liquid helium temperatures in solid $\mathrm{ND}_{3},{ }^{64}$ the implied value of $K_{0}$ from fitting Eq. 1 is too large by a factor of $\sim 5$. This discrepancy is likely due to the very simple model of the vibrational spectrum represented by Eq. 2.

\section{Calculated high pressure behaviours}

Geometry optimizations of the EMA and EHA structures were carried out over the range -0.75 to $20 \mathrm{GPa}$. Supplementary Table S5 compares the zero-pressure unit-cell parameters from the DFT calculations with the nearest available experimental data; $10 \mathrm{~K}$ for EMA and $70 \mathrm{~K}$ for EHA. It is worth noting that the directions in which the differences are greatest correspond with hydrogen bonded motifs (tapes or sheets) in each structure whereas directions in which the interactions are very weak tend to be reproduced more accurately. This arises due to an overestimation of the H-bond strength by this computational method..

The calculated variation in unit-cell parameters with pressure is shown in Supplementary Figures S4 (EMA) and S5 (EHA) where it may be observed that discontinuities occur in both compounds.

In EMA, the calculations expose a considerable shortening of the very long and weak N$\mathrm{H} 3 \cdots \mathrm{O} 1$ interaction to the point where it develops quickly into a regular hydrogen bond. This coincides with ethanol atom $\mathrm{O} 1$ shedding $\mathrm{H} 9$, which is transferred to the ammonia molecule to form an ammonium ion (Fig. 13). The effect of this is to shorten the interactions in the $R_{2}^{2}(8)$ rings and thus shrink both the $b$-axis and the $c$-axis of the crystal. The resulting salt, ammonium 
ethoxide, undergoes no further rearrangement up to $25 \mathrm{GPa}$ and indeed may be 'decompressed' in silico down to $2 \mathrm{GPa}$ with only a very minor structural distortion. The curves of total energy as a function of volume, $E(\mathrm{~V})$, were fitted with integrated forms of a $4^{\text {th }}$-order logarithmic equation of state: ${ }^{69}$

$$
E(P)=V_{0}\left[\frac{a \ln ^{2} x}{2}+\frac{b \ln ^{3} x}{3}+\frac{c \ln ^{4} x}{4}\right]+E_{0}
$$

where $V_{0}$ and $E_{0}$ are the zero pressure volume and total energy, respectively, $x=V_{0} / V_{\mathrm{P}}$, and

$$
\begin{gathered}
a=K_{0} \\
b=\frac{K_{0}\left(K_{0}^{\prime}-2\right)}{2} \\
c=\frac{K_{0}^{2} K_{0}^{\prime \prime}+K_{0}+K_{0}\left(K_{0}^{\prime}-2\right)+K_{0}\left(K_{0}^{\prime}-2\right)^{2}}{6}
\end{gathered}
$$

$K_{0}$ is the zero-pressure incompressibility (or isothermal bulk modulus); the prime and doubleprime terms are the first and second pressure derivatives of $K_{0}$, respectively.
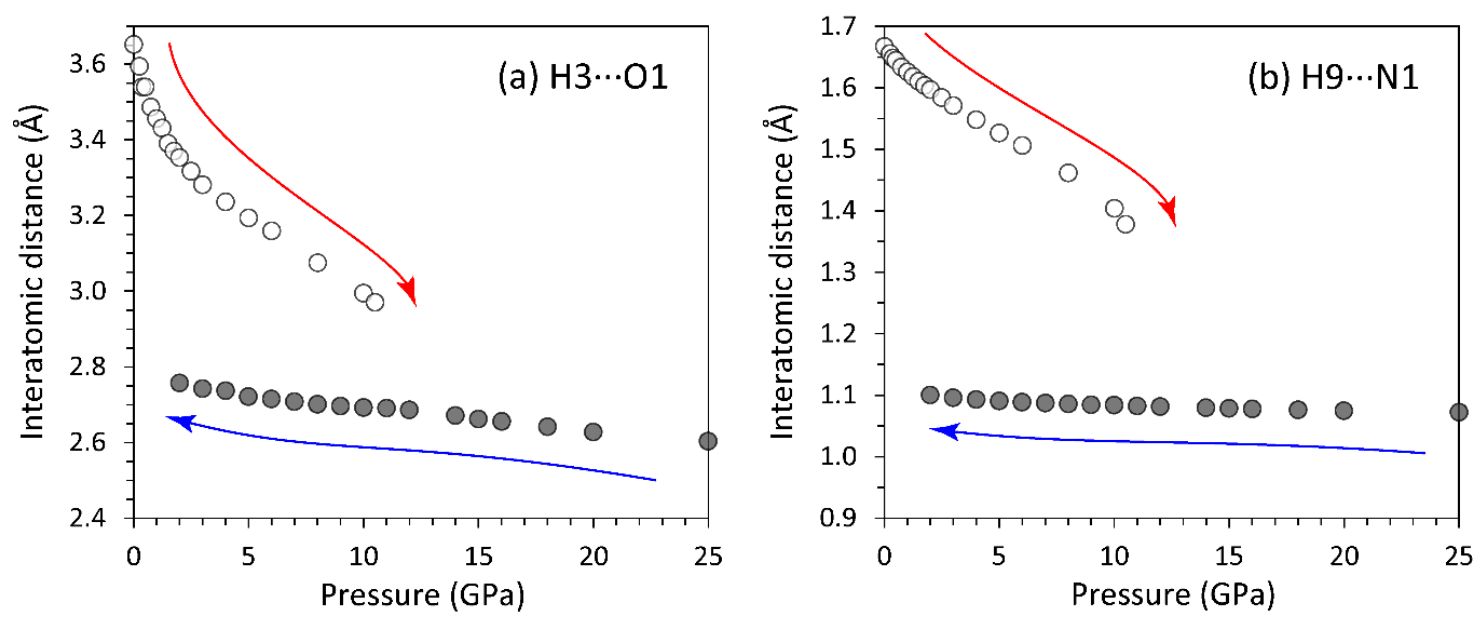

\section{Figure 13}

Pressure dependence of two interatomic contacts in ethanol mono-ammoniate derived from DFT geometry optimizations. The open symbols correspond with the molecular form of the crystal and 
the filled circles with the ionic form. Arrows indicate calculations done sequentially on pressure increase (red) and decrease (blue). Panel (a) shows the shortening of the very weak N1-H3 $\cdots \mathrm{O} 1$ intermolecular interaction up to the point where is develops (and then persists) as a 'normal' hydrogen bond. Panel (b) shows the transfer of the hydroxyl hydrogen atom to $\mathrm{N}$ to form an ammonium ion.

The fits of Eqs. 3-6 are shown in Figure 14 and the fit parameters are provided in Suppl. Table S6. The enthalpies in the athermal limit, $H=E+P V$, derived from the equation of state and normalised to the enthalpy of the molecular phase, reveal that the thermodynamic equilibrium between the neutral and ionic phases is at $4.46 \pm 0.25 \mathrm{GPa}$ (Fig. 15a).
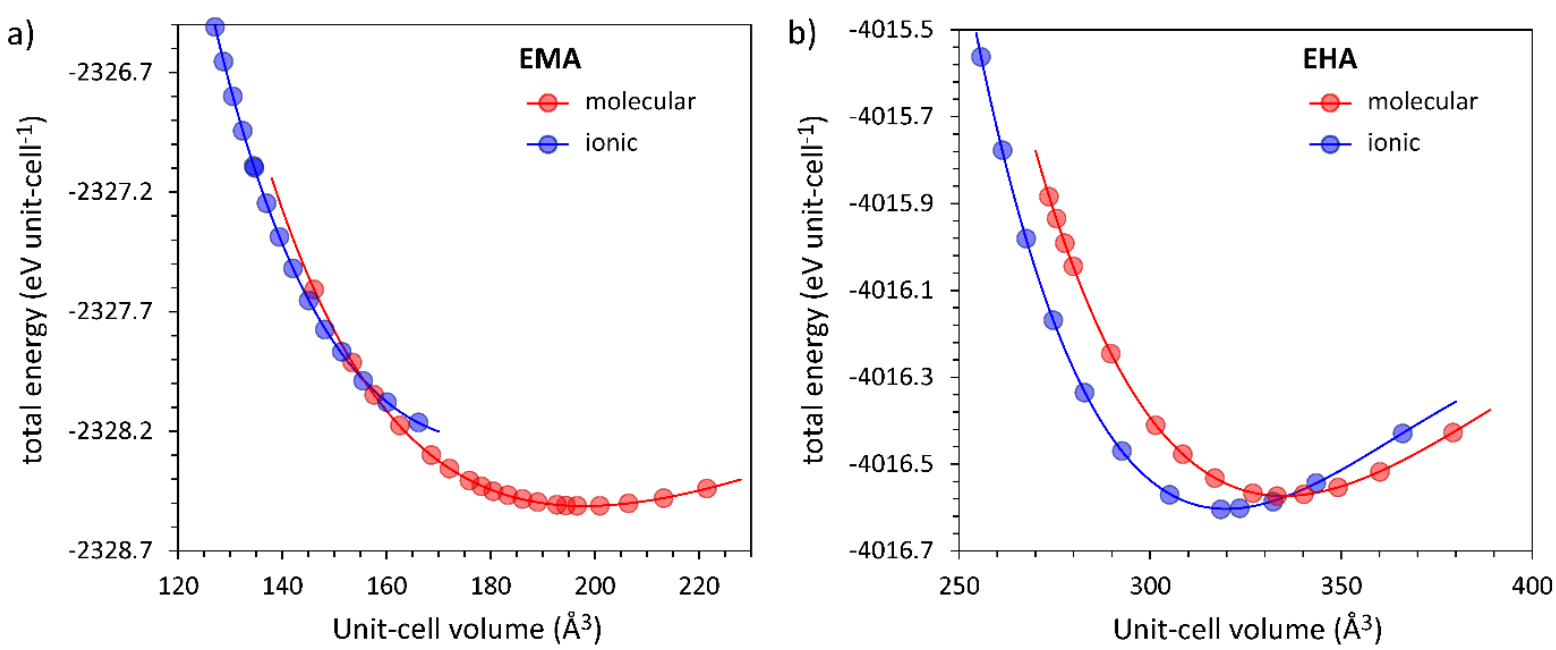

\section{Figure 14}

Curves of total electronic energy against unit-cell volume for molecular and ionic phases of ethanol mono-ammoniate (a) and ethanol hemi-ammoniate (b). Symbols are the results of DFT calculations and the solid lines are $4^{\text {th }}$ order logarithmic equations of state (see text).

The discontinuities in the unit-cell parameters of EHA occur at a lower pressure than those in EMA. Nevertheless, the origin of the phenomenon is the same, a proton transfer, although here we find a coupled transfer of two protons. In EHA, there is a proton transfer between the two ethanol molecules ( $\mathrm{H} 9$ is swapped from $\mathrm{O} 1$ to $\mathrm{O} 2$ ) concurrent with a proton transfer between ethanol and ammonia (H15 is swapped from $\mathrm{O} 2$ to N1), the result being a partially ionic compound, or ionic co-crystal (according to the currently-accepted definition. ${ }^{70,71}$ ); ethanol ammonium ethoxide. 
Energy-volume curves and enthalpies of the molecular and ionic forms of EMH were computed and fitted with equations of state (Figure 14, Suppl. Table S6). In marked contrast with EMA, the partially ionic form of EHA is found to be the ground state at zero pressure, being lower in enthalpy then the molecular phase by $1.4(8) \mathrm{kJ} \mathrm{mol}^{-1}$. Indeed the thermodynamic equilibrium between the two phases occurs at $-0.30 \pm 0.24 \mathrm{GPa}$ (Fig. 15b).

The calculated bulk moduli of the two molecular phases, 10.8(2) GPa for EMA and 11.9(2) GPa for EHA, are expected to be $\sim 5 \%$ stiffer than the real materials, by virtue of the $c a .1 .5 \%$ over-binding produced by the DFT method. The development of shorter, stronger hydrogenbonded interactions in the ionic phases leads to these crystals having higher zero-pressure bulk moduli; 15(1) GPa for ionic EMA and 14.0(1) GPa for partially ionic EMA.
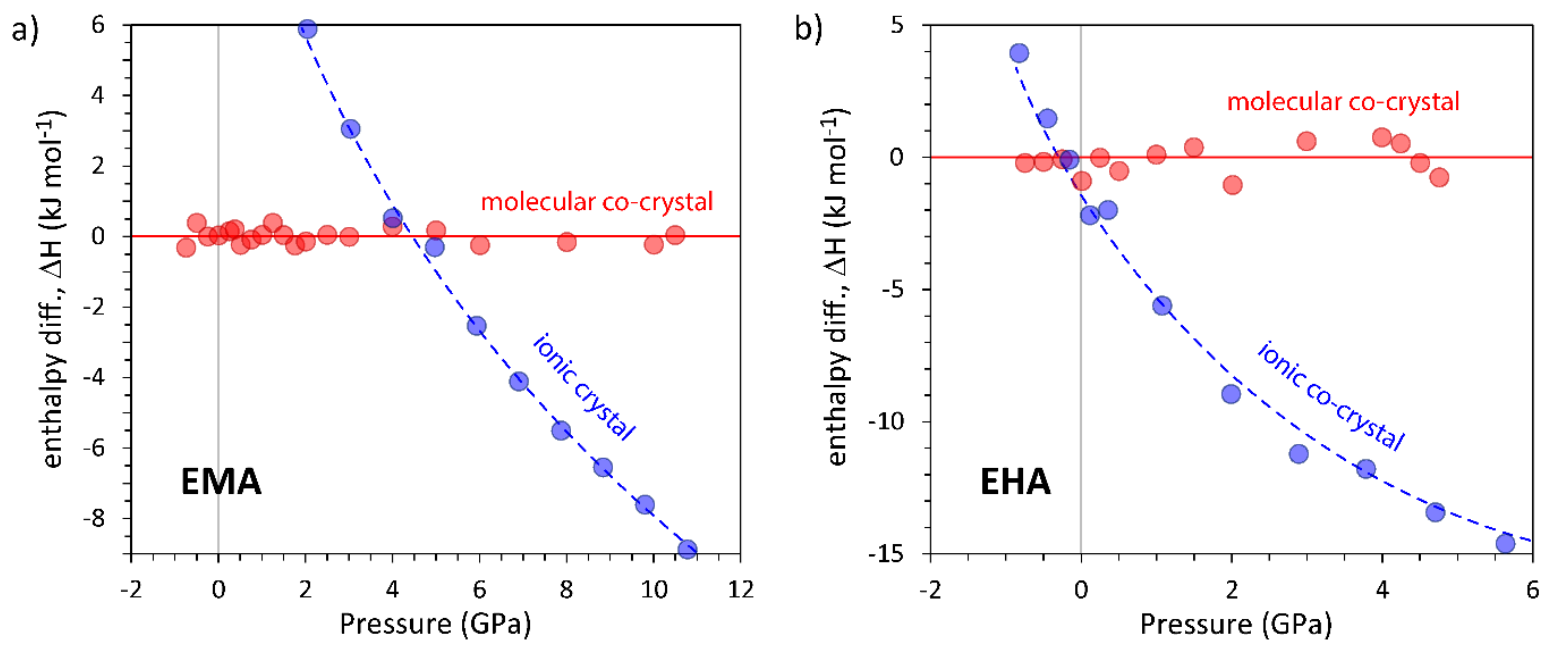

\section{Figure 15}

Enthalpies in the athermal limit of the molecular and ionic phases of ethanol mono-ammoniate (a) and ethanol hemi-ammoniate (b), normalised to the enthalpy of the molecular forms. At any particular pressure, the phase with the lowest enthalpy is the thermodynamically stable form. Symbols are the results of DFT calculations and the solid/dashed lines are derived from $4^{\text {th }}$ order logarithmic equations of state (see text).

\section{Concluding remarks}

The results of this work confirm Broderson's discovery of ethanol hemi-ammoniate and ethanol mono-ammoniate but do not support the existence of his suggested solid solution. Similarly, the 
kink in the mono-ammoniate liquidus on the ammonia-rich side does not appear to be due to the existence of a di-ammoniate (at least in the deuterated material). Hence the ethanol-ammonia binary system ${ }^{16}$ is essentially the same as the methanol-ammonia system, ${ }^{15}$ comprising the pure end-members, a hemi-ammoniate and mono-ammoniate. This stands in contrast to the much simpler binary systems of ammonia with propanols and butanols, ${ }^{17}$ and the more complex binary system of ammonia with phenol. ${ }^{18,21}$

Both of the molecular ammoniates are triclinic, crystallising in space-group $P \overline{1}$. Each is characterised by 4-sided hydrogen bonded rings. In EMA, these form tapes running along the $b$ axis with only dispersion-based interactions between them. In EHA, the 4-sided rings are linked by 6 -sided rings to form sheets in the $a$ - $b$ plane. Like EMA, however, the interactions between the sheets are mediated entirely by dispersion forces.

As a consequence of these highly anisotropic structural elements, the bulk physical properties are also highly anisotropic. The measured thermal expansion of EMA, as well as the calculated incompressibilities of EMA and EHA show that the orientation of the thermal expansion and compressibility maxima correspond with the directions where intermolecular interactions are weakest, as one would expect.

Calculations also indicate that both phases will undergo proton transfer reactions to form a pure salt (EMA $\rightarrow$ ammonium ethoxide) or an ionic co-crystal (EHA $\rightarrow$ ethanol ammonium ethoxide). The equilibria for these two reactions are predicted to be at $+4.46 \mathrm{GPa}$ and $-0.30 \mathrm{GPa}$, respectively. These results highlight the likely importance of the stoichiometry and the local chemical environment over simple rules based on $p K_{a}$ differences between the acidic and basic components. $^{72-75}$

I and others have predicted the occurrence of similar complete and partial proton transfer reactions in ammonia hydrates, ${ }^{76-78}$ including the transformation of ammonia monohydrate (AMH) to ammonium hydroxide at $\sim 5.5 \mathrm{GPa}^{79}$ and ammonia hemihydrate (AHH) to ammonium hydroxide ammoniate at $\sim 12.5 \mathrm{GPa}^{78}$ In reality these processes are interrupted by polymorphic phase transitions at much lower pressures. ${ }^{80-83} \mathrm{AMH}$ is particularly interesting, however, because the disordered nature of one of the high-pressure molecular phases is known explicitly to hinder the formation of an ionic phase. ${ }^{84}$ Clearly, small alcohol molecules offer a more fruitful avenue for permitting proton transfer to ammonia at lower pressures in very simple molecular crystals, where they are less likely to be interrupted by polymorphic transformations. 
If this particular combination of DFT methods (ultrasoft pseudopotentials, PBE + TS, convergence criteria) are accurate, then the coupled proton transfer in EMA may occur simply on cooling. Thermally-induced proton transfer is known to occur in other systems. ${ }^{85}$ However, considering the relatively low temperature in this instance, the transition could be kineticallyhindered, resulting in the formation only of micro-domains of partially ionic material in a matrix of molecular domains. It is therefore tempting to attribute the substantial size/strain broadening of the Bragg peaks and the large changes in thermal expansion to such a proton transfer. Structurefactor calculations indicate that one would also expect large changes in peak intensities, such as a four-fold increase in the 001 peak at $\sim 9.4 \AA$ and the disappearance of the 100 peak at $\sim 5.2 \AA$ for example; such changes are not apparent in the data. It is thus more plausible that the observations collected to date are related to the dynamics of the methyl groups rather than proton transfer but further work is necessary to evaluate these competing hypotheses.

Long-duration studies with protracted periods of annealing may be required in order to achieve substantial degrees of transformation to any partially ionic phase. Simultaneous diffraction and IR or Raman spectroscopic methods affords the opportunity to confirm whether the crystal really exhibits a switch from a molecular to ionic co-crystal on cooling at ambient pressure. Other measurements - ideally with single crystals - will provide insight into the possible role of the methyl groups in the thermal expansion behaviour.

Ionic co-crystals of the form $\mathrm{M}^{+}$alkoxide ${ }^{-}$alcohol solvate have been known for a long time in metal organic systems, ${ }^{86-93}$ the most recent structure to be described being di-ethanol sodium ethoxide in $2020 .{ }^{94}$ It is noteworthy that only when $M=\mathrm{NH}_{4}$ is there a possibility for a purely molecular analogue of the ionic co-crystal to occur and for a transition between the two forms to be observed.

The potential for proton transfer to ammonia from a comparably weak acid such as ethanol at ambient pressure suggests that there may be extensive ammonium salt formation amongst compounds of the simplest alcohols. Even if modest (few GPa) pressures are required, this can readily be generated in hypervelocity impacts. Gaffney and Matson ${ }^{95}$ observed that the combination of low shock pressures involved in the production of high-pressure ice polymorphs, the concomitant low post-shock temperatures, and the low ambient temperatures (even at noon at the subsolar point) for all icy objects at or beyond the orbit of Saturn, would lead to the retention of large fractions of shock-induced icy polymorphs. Since many molecular solids are known to 
adopt high-pressure structures that may also be preserved on pressure release, provided the temperature is $<150 \mathrm{~K}$, the phenomenon described by Gaffney and Matson will not be restricted only to water ices: shock-induced ionic forms of alcohol ammoniates could also be present in icy regoliths in the outer solar system. This may be an important additional mechanism to reactions with simple carboxylic acids, adsorption onto clay minerals and/or UV photolysis for the generation of $\mathrm{NH}_{4}^{+}$spectroscopic signatures in remotely sensed data from interstellar, cometary and planetary ices.

There is thus a need for both static and dynamic high-pressure studies of these materials in order to determine their likely production, preservation and spectroscopic signatures. There have been some shock equation-of-state studies of water-ammonia-ethanol mixtures carried out recently, ${ }^{96}$ with application to the interiors of the ice giant planets, Uranus and Neptune. Furthermore, work on the spectroscopic fingerprints of molecular ices needs to extend beyond single-component substances ${ }^{97}$ to the kinds of simple multi-component materials likely to occur in nature, particularly after thermal or shock processing. Having a broad range of wellcharacterized shock-induced phases that can be detected by remote sensing offers potentially the most robust means of constraining peak shock pressures and post-shock thermal history.

\section{Acknowledgements}

I wish to thank the ISIS neutron spallation facility for the equipment and resources used to carry out this work, including the SCARF high-performance computing cluster, as part of beam-time allocation RB 1720183. I thank Dr Sarah Youngs for providing backup ethanol- $d_{6}$ at very short notice and Dr Alex Gibbs for helping with the sample preparation.

\section{Data availability}

The author declares that all processed numerical data required to support the conclusions of this work are provided in the Supplementary Information.

The raw experimental data are archived at https://doi.org/10.5286/ISIS.E.95699847

\section{Supporting information available:}

Supplementary electronic figures and tables. 
Crystallographic information files (CIFs) containing the refined structural models and processed data for ethanol mono- and hemi-ammoniate, including CheckCIF reports.

CIFs containing the zero-pressure DFT optimized structures of molecular ethanol mono- and hemi-ammoniate as well as the partially ionic co-crystal of ethanol ammonium ethoxide.

\section{References}

(1) Todorova, T.; Delley, B. Molecular crystals: a test system for weak bonding. J. Phys. Chem. C. 2010, 114, 20523-20530. doi:10.1021/jp1049759

(2) Boese, R.; Bläser, D.; Jansen, G. Synthesis and Theoretical Characterization of an AcetyleneAmmonia Cocrystal. J. Am. Chem. Soc. 2009, 131, 2104-2106. doi:10.1021/ja8059705

(3) Fortes, A. D.; Suard, E.; Knight, K. S. Negative linear compressibility and massive anisotropic thermal expansion in methanol monohydrate. Science 2011, 331, 742-746. doi:10.1126/science. 1198640

(4) Charnley, S. B.; Kress, M. E.; Tielens, A. G. G. M.; Millar, T. J. Interstellar alcohols. Astrophys. J. 1995, 448, 232-239. doi:10.1086/175955

(5) Rivilla, V. M.; Beltrán, M. T.; Cesaroni, R.; Fontani, F.; Codella, C.; Zhang, Q. Formation of ethylene glycol and other complex organic molecules in star-forming regions. Astron. Astrophys. 2017, 598, article number A59. doi:10.1051/0004-6361/201628373

(6) Allamandola, L. J.; Bernstein, M. P.; Sandford, S. A.; Walker, R. L. Evolution of interstellar ices. In Composition and Origin of Cometary Materials. Springer, Dordrecht, 1999; pp 219-232. (7) Knacke, R. F.; McCorkle, S.; Puetter, R. C.; Erickson, E. F.; Krätschmer, W. Observation of interstellar ammonia ice. Astrophys. J. 1982, 260, 141-146.

(8) Gürtler, J.; Klaas, U.; Henning, T.; Abrahám, P.; Lemke, D.; Schreyer, K.; Lehmann, K. Detection of solid ammonia, methanol, and methane with ISOPHOT. Astron. Astrophys. 2002, 390, 1075-1087. doi:10.1051/0004-6361:20020772

(9) Biver, N.; Bockelée-Morvan, D.; Moreno, R.; Crovisier, J.; Colom, P.; Lis, D.C.; Sandqvist, A.; Boissier, J.; Despois, D.; Milam, S.N. Ethyl alcohol and sugar in comet C/2014 Q2 (Lovejoy). Sci. Adv. 2015, 1, article number e1500863. doi:10.1126/sciadv.1500863

(10) Bockelée-Morvan, D.; Biver, N. The composition of cometary ices. Phil. Trans. Roy. Soc. A 2017, 375, article number 20160252. doi:10.1098/rsta.2016.0252 
(11) Altwegg, K.; Balsiger, H.; Fuselier, S. A. Cometary chemistry and the origin of icy solar system bodies: the view after Rosetta. Ann. Rev. Astron. Astrophys. 2019, 57, 113-55. doi:10.1146/annurev-astro-091918-104409

(12) Shock, E. L.; McKinnon, W. B. Hydrothermal processing of cometary volatilesApplications to Triton. Icarus, 1993, 106, 464-477. doi:10.1006/icar.1993.1185

(13) Brown, M. E.; Calvin, W. M. Evidence for crystalline water and ammonia ices on Pluto's satellite Charon. Science 2000, 287, 107-109. doi:10.1126/science.287.5450.107

(14) Grundy, W. M.; Binzel, R. P.; Buratti, B. J.; Cook, J. C.; Cruikshank, D. P.; Dalle Ore, C. M.; Earle, A. M. et al. Surface compositions across Pluto and Charon. Science 2016, 351, article number aad9189. doi:10.1126/science.aad9189

(15) Kargel, J. S. Ammonia-water volcanism on icy satellites: Phase relations at 1 atmosphere. Icarus, 1992, 100, 556-574. doi:10.1016/0019-1035(92)90118-Q

(16) Broderson, H. J. The fusion curve of ammonia and ethyl alcohol. MA Thesis, University of Kansas, 1911. http://hdl.handle.net/1808/8452

(17) Cady, H. P.; Jones, E. A. The Fusion Curves for the Systems Ammonia-Propyl Alcohols and Ammonia-Butyl Alcohols. J. Phys. Chem. 1933, 37, 303-320. doi:10.1021/j150345a003 (18) Briner, E.; Agathon, O.; Ferrero, A. Sur les combinaisons d'addition entre les phénols et l'ammoniac I. Helv. Chim. Acta, 1926, 9, 905-912. doi:10.1002/hlca.192600901121

(19) Fortes, A. D.; Wood, I. G.; Knight, K. S. The crystal structure of perdeuterated methanol monoammoniate $\left(\mathrm{CD}_{3} \mathrm{OD} \cdot \mathrm{ND}_{3}\right)$ determined from neutron powder diffraction data at 4.2 and 180 K. J. Appl. Crystallgr. 2009, 42, 1054-1061. doi:10.1107/S0021889809035705 (20) Fortes, A. D.; Wood, I. G.; Knight, K. S. (2010). The crystal structure of perdeuterated methanol hemiammoniate $\left(\mathrm{CD}_{3} \mathrm{OD} \cdot 0.5 \mathrm{ND}_{3}\right)$ determined from neutron powder diffraction data at 4.2 and 180 K. J. Appl. Crystallgr. 2010, 43, 328-336. doi:10.1107/S0021889810005595 (21) Fortes, A. D. Structures of phenol-ammonia and phenol-water compounds. STFC ISIS Neutron and Muon Source, 2019, RB1920009. doi:10.5286/ISIS.E.RB1920009 (22) Ibberson, R.M. Design and performance of the new supermirror guide on HRPD at ISIS. Nucl. Instr. Methods A 2009, 600, 47-49. doi:10.1016/j.nima.2008.11.066 (23) Arnold, O., \& 27 co-authors. Mantid-Data analysis and visualization package for neutron scattering and $\mu \mathrm{SR}$ experiments. Nucl. Instrum. Methods A 2014, 764, 156-166. doi: 10.1016/j.nima.2014.07.029 
(24) Albinati, A.; Willis, B. T. M. The Rietveld method in neutron and X-ray powder diffraction. J. Appl. Crystallogr. 1982, 15, 361-374. doi:10.1107/S0021889882012187

(25) Le Bail, A. Whole powder pattern decomposition methods and applications: A retrospection. Powder Diffr. 2005, 20, 316-326. doi:10.1154/1.2135315

(26) Larson, A. C.; Von Dreele, R. B. General Structure Analysis System (GSAS). Los Alamos National Laboratory Report, LAUR 86-748, 1994.

(27) Toby, B. H. EXPGUI, a graphical user interface for GSAS. J. Appl. Crystallogr. 2001, 34, 210-213. doi:10.1107/S0021889801002242

(28) Hohenberg, P.; Kohn, W. Inhomogeneous electron gas. Phys. Rev. 1964, 136, B864-B871. doi:10.1103/PhysRev.136.B864

(29) Kohn, W.; Sham, L. J. Self-consistent equations including exchange and correlation effects. Phys. Rev. 1965, 140, A1133-A1138. doi:10.1103/PhysRev.140.A1133

(30) Payne, M. C.; Teter, M. P.; Allan, D. C.; Arias, T. A.; Joannopoulos, J. D. Iterative minimization techniques for $a b$ initio total-energy calculations: molecular dynamics and conjugate gradients. Rev. Mod. Phys. 1992, 64, 1045-1097. doi:10.1103/RevModPhys.64.1045 (31) Segall, M. D.; Lindan, P. J. D.; Probert, M. J.; Pickard, C. J.; Hasnip, P. J.; Clark, S. J.; Payne, M. C. First-principles simulation: ideas, illustrations and the CASTEP code. J. Phys. Cond. Matter 2002, 14, 2717-2744. doi:10.1088/0953-8984/14/11/301

(32) Clark, S. J.; Segall, M. D.; Pickard, C. J.; Hasnip, P. J.; Probert, M. I. J.; Refson, K.; Payne, M. C. First principles methods using CASTEP. Z. Krist. 2005, 220, 567-570. doi:10.1524/zkri.220.5.567.65075

(33) Perdew, J. P.; Burke, K.; Ernzerhof, M. Generalized gradient approximation made simple. Phys. Rev. Lett. 1996, 77, 3865-3868. doi:10.1103/PhysRevLett.77.3865

(34) Perdew, J. P.; Burke, K.; Ernzerhof, M. Generalized gradient approximation made simple. Phys. Rev. Lett. 1997, 78, 1396. doi:10.1103/PhysRevLett.78.1396

(35) Tkatchenko,A.; Scheffler, M. Accurate molecular van der Waals interactions from groundstate electron density and free-atom reference data. Phys. Rev. Lett., 2009, 102, 073005-073008. doi:10.1103/PhysRevLett.102.073005

(36) Fortes, A. D. Phenol hemihydrate: redetermination of the crystal structure by neutron powder diffraction, Hirschfeld surface analysis and characterization of the thermal expansion. Acta Crystallogr. E 2020, 76, 1062-1069. doi:10.1107/S2056989020007719 
(37) Pfrommer, B. G.; Cote, M.; Louie, S. G.; Cohen, M. L. Relaxation of crystals with the Quasi-Newton method. J. Comp. Phys. 1997, 191, 233-240. doi:10.1006/jcph.1996.5612 (38) Rutter, M. J. C2X: A tool for visualisation and input preparation for Castep and other electronic structure codes. Comput. Phys. Comm. 2018, 225, 174-179. doi:10.1016/j.cpc.2017.12.008

(39) Momma, K.; Izumi, F. VESTA 3 for three-dimensional visualization of crystal, volumetric and morphology data. J. Appl. Cryst. 2011, 44, 1272-1276. doi:10.1107/S0021889811038970 (40) Vega, D.; Almeida, D. AIM-UC: An application for QTAIM analysis. J. Comput. Meth. Sci. Eng. 2014, 14, 131-136. doi:10.3233/JCM-140491

(41) Louër, D.; Boultif, A. Powder pattern indexing and the dichotomy algorithm. Z. Kristallogr. Suppl. 2007, 26, 191-196. doi:10.1524/9783486992540-030

(42) De Wolff, P.M. (1968): A simplified criterion for the reliability of a powder pattern indexing. J. Appl. Crystallogr. 1968, 5, 108-113. doi:10.1107/S002188986800508X (43) Smith, G. S.; Snyder, R. L. F(N): a criterion for rating powder diffraction patterns and evaluating the reliability of powder-pattern indexing, J. Appl. Crystallogr. 1979, 12, 60-65. doi:10.1107/S002188987901178X

(44) Jönsson, P. G. Hydrogen bond studies. CXIII. The crystal structure of ethanol at 87 K. Acta Crystallogr. B 1976, 32, 232-235. doi:10.1107/S0567740876002653

(45) Hewat, A. W.; Riekel, C. The crystal structure of deuteroammonia between 2 and $180 \mathrm{~K}$ by neutron powder profile refinement. Acta Crystallogr. A 1979, 35, 569-571.

doi:10.1107/S0567739479001340

(46) Favre-Nicolin, V.; Černý, R. FOX, 'free objects for crystallography': a modular approach to $a b$ initio structure determination from powder diffraction. J. Appl. Crystallogr. 2002, 35, 734743. doi:10.1107/S0021889802015236

(47) Favre-Nicolin, V.; Černý, R. A better FOX: using flexible modeling and maximum likelihood to improve direct-space $a b$ initio structure determination from powder diffraction. $Z$. Krist. 2004, 219, 847-856. doi:10.1524/zkri.219.12.847.55869

(48) Etter, M. C.; MacDonald, J. C.; Bernstein, J. Graph-set analysis of hydrogen-bond patterns in organic crystals. Acta Crystallogr. B. 1990, 46, 256-262. doi:10.1107/S0108768189012929 
(49) Mantina, M.; Chamberlin, A. C.; Valero, R.; Cramer, C. J.; Truhlar, D. G. Consistent van der Waals radii for the whole main group. J. Phys. Chem. A 2009, 113, 5806-5812. doi:10.1021/jp8111556

(50) Wick, C. R.; Clark, T. On bond-critical points in QTAIM and weak interactions. J. Mol. Model. 2018, 24, article number 142. doi:10.1007/s00894-018-3684-X

(51) Jabłoński, M. On the uselessness of bond paths linking distant atoms and on the violation of the concept of privileged exchange channel. Chem. Open. 2019, 8, 497-507. doi:10.1002/open.201900109

(52) Shahbazian, S. Why bond critical points are not "bond" critical points. Chem. Eur. J. 2018, 24, 5401-5405. doi:10.1002/chem.201705163

(53) Taylor, R. Identifying intermolecular atom $\cdots$ atom interactions that are not just bonding but also competitive. CrystEngComm. 2020, doi:10.1039/d0ce00270d

(54) Desiraju, G. R. The C-H - O O hydrogen bond in crystals: what is it? Acc. Chem. Res. 1991, 24, 290-296. doi:10.1021/ar00010a002

(55) Steiner, T.; Desiraju, G. R. Distinction between the weak hydrogen bond and the van der Waals interaction. Chem. Comm. 1998, 891-892. doi:10.1039/A708099I

(56) Koch, U.; Popelier, P. L. A. Characterization of $\mathrm{C}-\mathrm{H}-\mathrm{O}$ hydrogen bonds on the basis of the charge density. J. Phys. Chem. 1995, 99, 9747-9754. doi:10.1021/j100024a016

(57) Ohashi, Y.; Burnham , C. W. Clinopyroxene lattice deformations: The roles of chemical substitution and temperature. Am. Mineral. 1973, 58, 843-849.

(58) Ohashi, Y. A program to calculate the strain tensor from two sets of unit-cell parameters. In, Hazen, R. M. and Finger, L. W., Comparative Crystal Chemistry. Wiley, New York, 1982; pp 92-102.

(59) Fortes, A. D.; Adams, M.; Knight, K. S.; Wood, I. G. Thermal expansion and simultaneous Raman spectroscopy of methanol ammoniates, $\mathrm{CD}_{3} \mathrm{OD} \cdot \mathrm{ND}_{3}$ and $2 \mathrm{CD}_{3} \mathrm{OD} \cdot \mathrm{ND}_{3}$. STFC ISIS

Neutron and Muon Source, 2010, RB1010210. doi:10.5286/ISIS.E.24079379

(60) Hashash, Y. M.; Yao, J. I. C.; Wotring, D. C. Glyph and hyperstreamline representation of stress and strain tensors and material constitutive response. Int. J. Num. Anal. Methods Geomech. 2003, 27, 603-626. doi:10.1002/nag.288

(61) WinTensor. http://cad4.cpac.washington.edu/WinTensorhome/WinTensor.htm 
(62) Olovsson, I.; Templeton, D. H. X-ray study of solid ammonia. Acta Crystallogr. 1959, 12, 832-836. doi:10.1107/S0365110X59002420

(63) Manzhelii, V. G.; Tolkachev, А. М. Тепловое Расширение Кристаллического Аммиака. Fiz. Tverd. Tela 1966, 8, 1035-1039.

(64) Manzhelii, V. G.; Tolkachev, A. M.; Krupskii, I. N.; Voitovich, E. I.; Popov, V. A.; Koloskova, L. A. Thermal properties of solid ND3. J. Low Temp. Phys. 1972, 7, 169-182. doi:10.1007/BF00629127

(65) Voitovich, E. I.; Tolkachev, A. M.; Manzhelli, V. G. Adiabatic compressibility of solid gases. J. Low. Temp. Phys. 1971, 5, 435-446. doi:10.1007/BF00629536

(66) Powell, B. M.; Dolling, G.; Pawley, G. S.; Leech, J. W. Lattice dynamics of ammonia. Can. J. Phys. 1980, 58, 1703-1711. doi:10.1139/p80-227

(67) Kiefte, H.; Breckon, S. W.; Penney, R.; Clouter, M. J. Elastic constants of ammonia by Brillouin spectroscopy. J. Chem. Phys. 1985, 83, 4738-4743. doi:10.1063/1.448999

(68) Fortes, A. D.; Brodholt, J. P.; Wood, I. G.; Vočadlo, L. Hydrogen bonding in solid ammonia from ab initio calculations. J. Chem. Phys, 2003, 118, 5987-5994. doi:10.1063/1.1555630 (69) Poirier, J. P.; Tarantola, A. A logarithmic equation of state. Phys. Earth Planet. Int. 1998, 109, 1-8. doi:10.1016/S0031-9201(98)00112-5

(70) Grothe, E.; Meekes, H.; Vlieg, E.; Ter Horst, J. H.; de Gelder, R. D. Solvates, salts, and cocrystals: a proposal for a feasible classification system. Cryst. Growth. Des. 2016, 16, 32373243. doi:10.1021/acs.cgd.6b00200

(71) Zhang, C.; Xiong, Y.; Jiao, F.; Wang, M.; Li, H. Redefining the term “cocrystal” and broadening its intention. Cryst. Growth Des. 2019, 19, 1471-1478. doi:10.1021/acs.cgd.8b01537 (72) Cruz-Cabeza, A. J. Acid-base crystalline complexes and the pKa rule. CrystEngComm 2012, 14, 6362-6365. doi:10.1039/C2CE26055G

(73) Pratik, S. M.; Datta, A. Nonequimolar mixture of organic acids and bases: an exception to the rule of thumb for salt or cocrystal. J. Phys. Chem. B 2016, 120, 7606-7613. doi:10.1021/acs.jpcb.6b05830

(74) Sedghiniya, S.; Soleimannejad, J.; Janczak, J. The salt-cocrystal spectrum in salicylic acidadenine: the influence of crystal structure on proton-transfer balance. Acta Crystallogr. C 2019, 75, 412-421. doi:10.1107/S205322961900312 
(75) Kavanagh, O.; Walker, G.; Lusi, M. Graph-set analysis helps to understand charge transfer in novel ionic cocrystal when the $\Delta$ pKa rule fails. Cryst. Growth Des. 2019, 19, 5308-5313. doi:10.1021/acs.cgd.9b00770

(76) Griffiths, G. I. G.; Misquitta, A. J.; Fortes, A. D.; Pickard, C. J.; Needs, R. J. High pressure ionic and molecular crystals of ammonia monohydrate within density functional theory. J. Chem. Phys. 2012, 137, article number 064506. doi:10.1063/1.4737887

(77) Jiang, X.; Wu, X.; Zheng, Z.; Huang, Y.; Zhao, J. Ionic and superionic phases in ammonia dihydrate $\mathrm{NH}_{3} \cdot 2 \mathrm{H}_{2} \mathrm{O}$ under high pressure. Phys. Rev. B 2017, 95, article number 144104. doi:10.1103/PhysRevB.95.144104

(78) Naden Robinson, V.; Marqués, M.; Wang, Y.; Ma, Y.; Hermann, A. Novel phases in ammonia-water mixtures under pressure. J. Chem. Phys. 2018, 149, article number 234501. doi:10.1063/1.5063569

(79) Fortes, A. D.; Brodholt, J. P.; Wood, I. G.; Vočadlo, L.; Jenkins, H. D. B. Ab initio simulation of ammonia monohydrate $\left(\mathrm{NH}_{3} \cdot \mathrm{H}_{2} \mathrm{O}\right)$ and ammonium hydroxide $\left(\mathrm{NH}_{4} \mathrm{OH}\right)$. J. Chem. Phys. 2001, 115, 7006-7014. doi:10.1063/1.1398104

(80) Fortes, A. Experimental and computational studies of solids in the ammonia-water system. $\mathrm{PhD}$ thesis, University of London, 2004.

(81) Fortes, A. D.; Wood, I. G.; Vočadlo, L.; Knight, K. S.; Marshall, W. G.; Tucker, M. G.; Fernandez-Alonso, F. Phase behaviour and thermoelastic properties of perdeuterated ammonia hydrate and ice polymorphs from 0 to $2 \mathrm{GPa}$. J. Appl. Crystallogr. 2009, 42, 846-866. doi:10.1107/S0021889809027897

(82) Fortes, A. D.; Suard, E.; Lemée-Cailleau, M. H.; Pickard, C. J.; Needs, R. J. Crystal structure of ammonia monohydrate phase II. J. Am. Chem. Soc. 2009, 131, 13508-13515. doi:10.1021/ja9052569

(83) Griffiths, G. I. G.; Fortes, A. D., Pickard, C. J.; Needs, R. J. Crystal structure of ammonia dihydrate II. J. Chem. Phys. 2012, 136, article number 174512. doi:10.1063/1.4707930 (84) Liu, C.; Mafety, A.; Queyroux, J. A.; Wilson, C. W.; Zhang, H.; Béneut, K.; Le Marchand, G.; Baptiste, B.; Dumas, P.; Garbarino, G.; Finocchi, F.; Loveday, J. S.; Pietrucci, F., Saitta, A. M.; Datchi, F.; Ninet, S. Topologically frustrated ionisation in a water-ammonia ice mixture. Nature Comms. 2017, 8, 1-8. doi:10.1038/s41467-017-01132-z 
(85) Jones, C. L.; Skelton, J. M.; Parker, S. C.; Raithby, P. R.; Walsh, A.; Wilson, C. C.; Thomas, L. H. Living in the salt-cocrystal continuum: indecisive organic complexes with thermochromic behaviour. CrystEngComm 2019, 21, 1626-1634. doi:10.1039/C8CE02066C (86) Mehring, M.; Berkei, M.; Schürmann, M. Crystal structure of $\mathrm{LiO}^{i} \mathrm{Pr} \cdot 5^{i} \mathrm{PrOH}-\mathrm{a}$ hydrogenbonded chain structure. Z. Anorg. Allgem. Chem. 2002, 628, 1975-1978. doi:10.1002/15213749(200209)628:9/10<1975::AID-ZAAC1975>3.0.CO;2-I

(87) Starikova, Z. A.; Yanovsky, A. I.; Turevskaya, E. P.; Turova, N. Y. The structure of the crystal solvate of magnesium methoxide with methanol, $\mathrm{Mg}(\mathrm{OMe})_{2} \cdot 3.5 \mathrm{MeOH}$. Polyhedron 1997, 16, 967-974. doi:10.1016/S0277-5387(96)00339-7

(88) Starikova, Z. A.; Turevskaya, E. P.; Turova, N. Y.; Yanovsky, A. I. The structure of the LiOMe.2MeOH crystal solvate. A new structural type for tetrameric alkoxides. J. Chem. Soc., Dalton Trans. 2000, 19, 3237-3238. doi:10.1039/B005782G

(89) Starikova, Z. A.; Turevskaya, E. P.; Turova, N. Y.; Yanovsky, A. I. On the structure of heterometallic methoxide $\mathrm{Li}_{2}(\mathrm{WO})_{2}(\mathrm{OMe})_{10} \cdot \mathrm{MeOH}$. Polyhedron 2002, 21, 193-195. doi:10.1016/S0277-5387(01)00981-0

(90) Chisholm, M. H.; Drake, S. R.; Naiini, A. A.; Streib, W. E. Synthesis and X-ray crystal structures of the one-dimensional ribbon chains $\left[\mathrm{MOBu}^{\mathrm{t}} \cdot \mathrm{Bu}^{\mathrm{t} O H}\right] \infty$ and the cubane species $\left[\mathrm{MOBu}^{\mathrm{t}}\right]_{4}(\mathrm{M}=\mathrm{K}$ and Rb). Polyhedron 1991, 103, 337-345. doi:10.1016/S02775387(00)80154-0

(91) Kessler, V. G.; Turevskaya, E. P.; Turova, N. Y. Interaction of magnesium and niobium methoxides. X-ray single crystal study of $\mathrm{Mg}_{2} \mathrm{Nb}_{2} \mathrm{O}_{2}(\mathrm{OMe})_{10}(\mathrm{MeOH})_{4}$. Polyhedron 2002, 21, 1629-1634. doi:10.1016/S0277-5387(02)01034-3

(92) Kessler, V. G.; Turova, N. Y.; Turevskaya, E. P. The structure of the bismuth ethoxide ethanol solvate. A new structural type for octameric alkoxides. Inorg. Chem. Comm. 2002, 5, 549-551. doi:10.1016/S1387-7003(02)00478-1

(93) Dinnebier, R. E.; Pink, M.; Sieler, J.; Norby, P.; Stephens, P. W. Powder Structure Solutions of the Compounds Potassium Phenoxide-Phenol: $\mathrm{C}_{6} \mathrm{H}_{5} \mathrm{OK} \cdot x \mathrm{C}_{6} \mathrm{H}_{5} \mathrm{OH}(x=2,3)$. Inorg. Chem. 1998, 37, 4996-5000. doi:10.1021/ic980350a

(94) Beske, M.; Tapmeyer, L.; Schmidt, M. U. (2020). Crystal structure of sodium ethoxide $\left(\mathrm{C}_{2} \mathrm{H}_{5} \mathrm{ONa}\right)$, unravelled after 180 years. Chem. Comm. 2020, 56, 3520-3523.

doi:10.1039/C9CC08907 
(95) Gaffney, E. S.; Matson, D. L. Water ice polymorphs and their significance on planetary surfaces. Icarus 1980, 44, 511-519. doi:10.1016/0019-1035(80)90041-X

(96) Guarguaglini, M.; Hernandez, J. -A.; Okuchi, T.; Barroso, P.; Benuzzi-Mounaix, A.; Bethkenhagen, M.; Bolis, R.; Brambrink, E.; French, M.; Fujimoto, Y.; Kodama, R.; Koenig, M.; Lefevre, F.; Myanishi, K.; Ozaki, N.; Redmer, R.; Sano, T.; Umeda, Y.; Vinci, T.; Ravasio, A. Laser-driven shock compression of "synthetic planetary mixtures" of water, ethanol, and ammonia. Sci. Rep. 2019, 9, article number 10155. doi:10.1038/s41598-019-46561-6 (97) Hudson, R. L.; Loeffler, M. J.; Ferrante, R. F.; Gerakines, P. A.; Coleman, F. M. Testing densities and refractive indices of extraterrestrial ice components using molecular structures organic compounds and molar refractions. Astrophys. J. 2020, 891, article number 22. doi:10.3847/1538-4357/ab6efa

TOC graphic

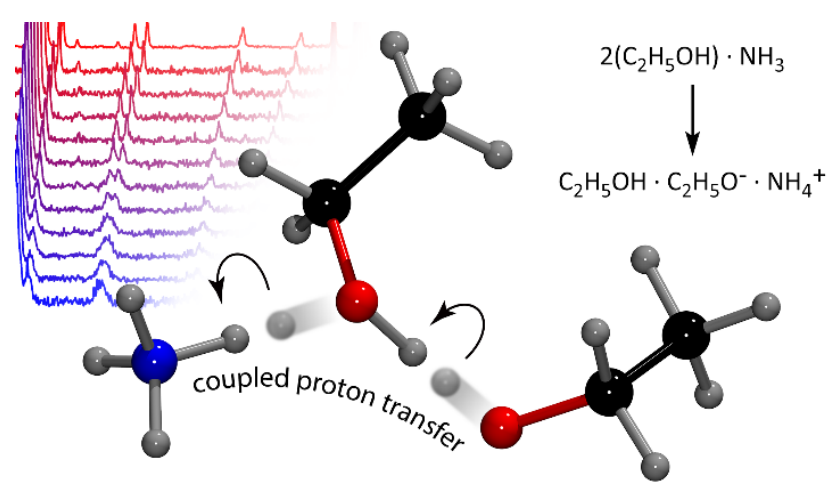




\title{
Electronic Supplementary Information
}

Co-crystals, salts and ionic co-crystals of ethanol and ammonia

\author{
A. Dominic Fortes, ${ }^{1,2, *}$ \\ ${ }^{1}$ ISIS Neutron \& Muon Spallation Source, Rutherford Appleton Laboratory, Harwell Science \\ and Innovation Campus, Chilton, Oxfordshire, OX11 0QX, United Kingdom. \\ ${ }^{2}$ Department of Earth Sciences, University College London, Gower Street, London WC1E \\ 6BT, United Kingdom. \\ *Corresponding author email: dominic.fortes@stfc.ac.uk
}




\section{Electronic Supplementary Information}

\section{Supplementary Figures}

\section{Figure S1}

Stack-plot of neutron powder diffraction data collected from ethanol hemi-ammoniate. The uppermost profile reports the long measurement at $175 \mathrm{~K}$ that was used for the structure refinement. Subsequent profiles moving down the stack are at $170 \mathrm{~K}$ and then in $10 \mathrm{~K}$ increments to $70 \mathrm{~K}$. The bottom profile $(70 \mathrm{~K})$ appears noisier due to a shorter counting time.

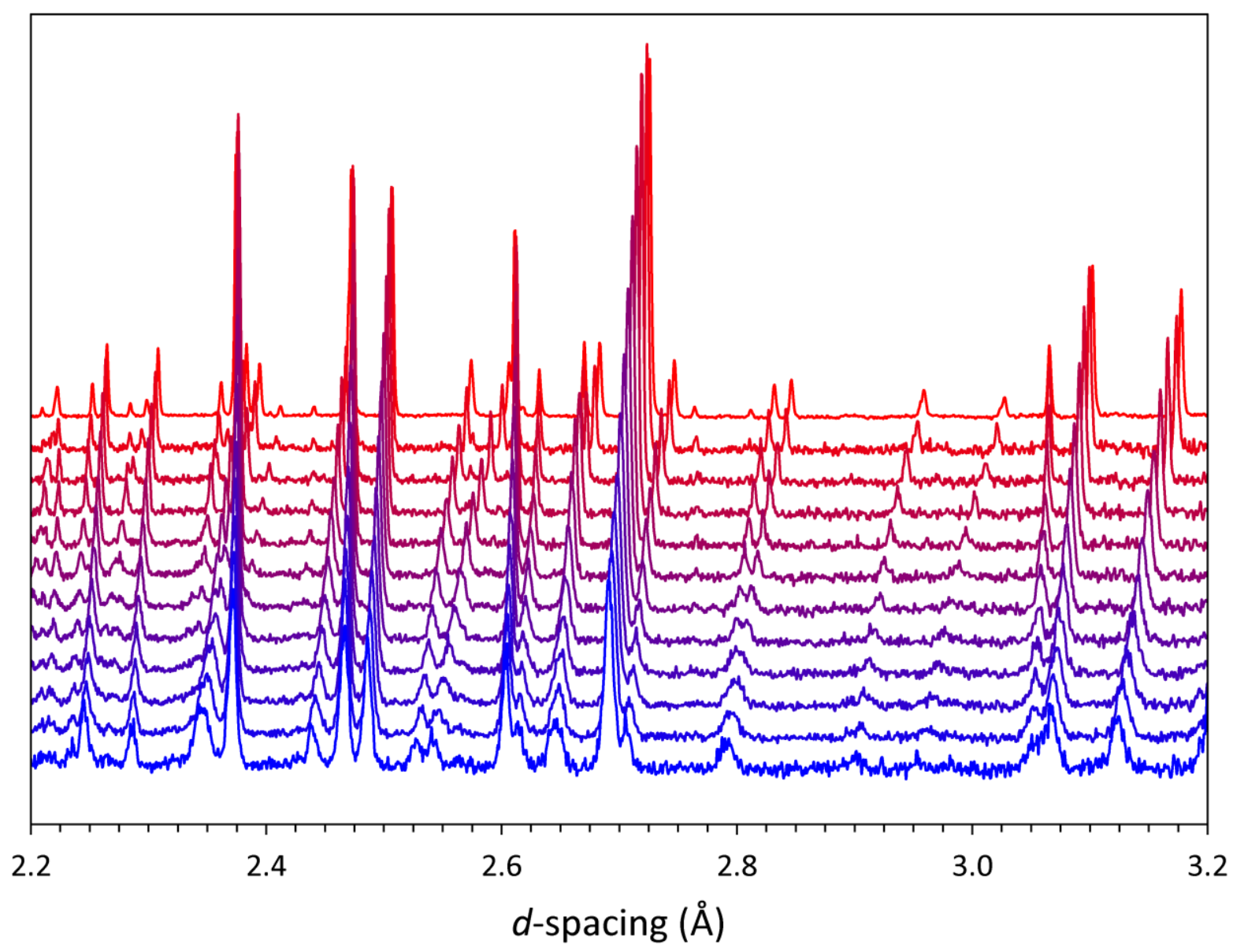




\section{Electronic Supplementary Information}

\section{Figure S2}

Unit-cell parameters of ethanol mono-ammoniate between 10 and $180 \mathrm{~K}$ : (a) $a$-axis; (b) $b$-axis; (c) $c$-axis; (d) angle $\alpha$; (e) angle $\beta$; (f) angle $\gamma$; (g) unit-cell volume (overleaf). Open circles represent the observations and the solid lines are Debye model or polynomial fits (see main text and Table S3)
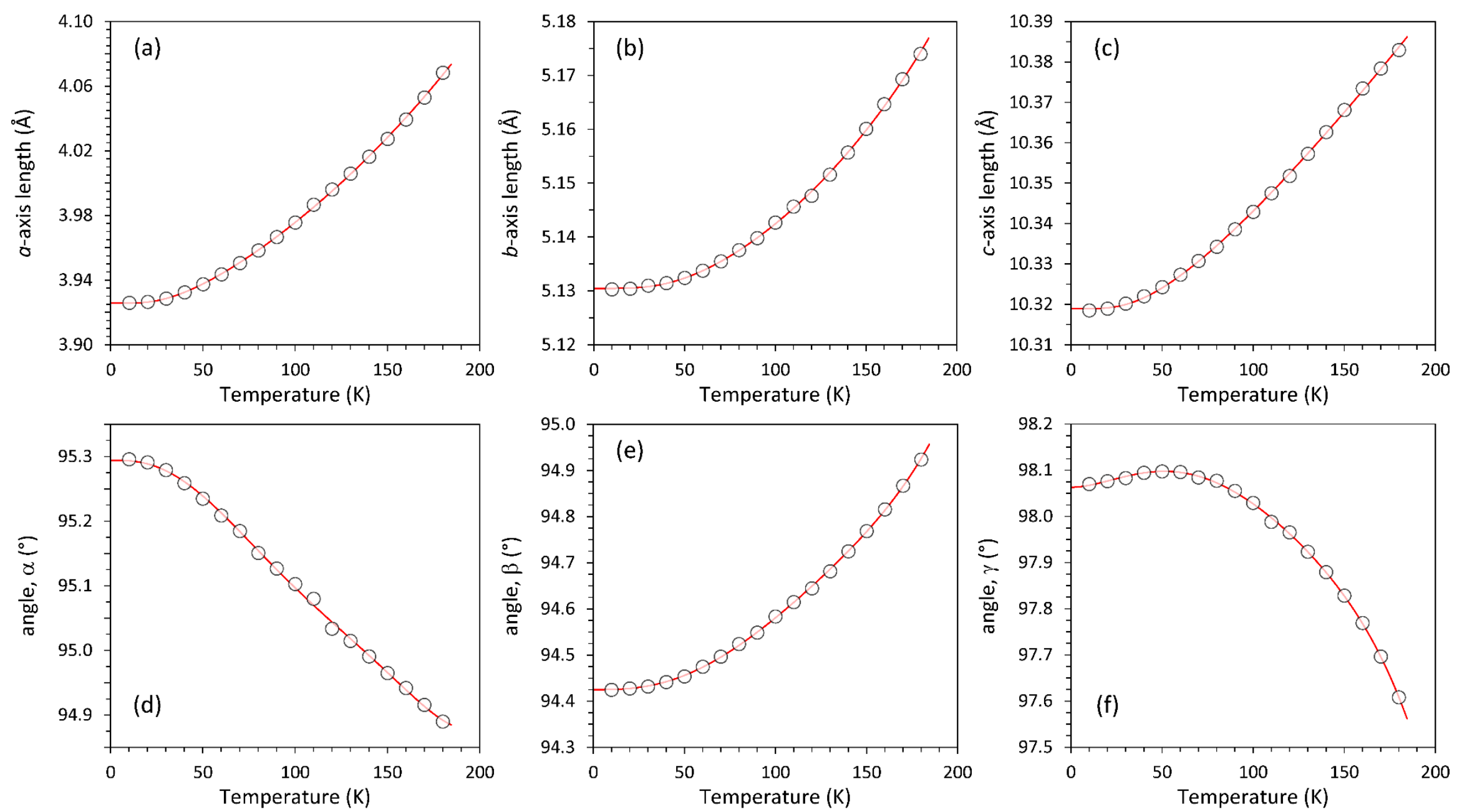
Electronic Supplementary Information

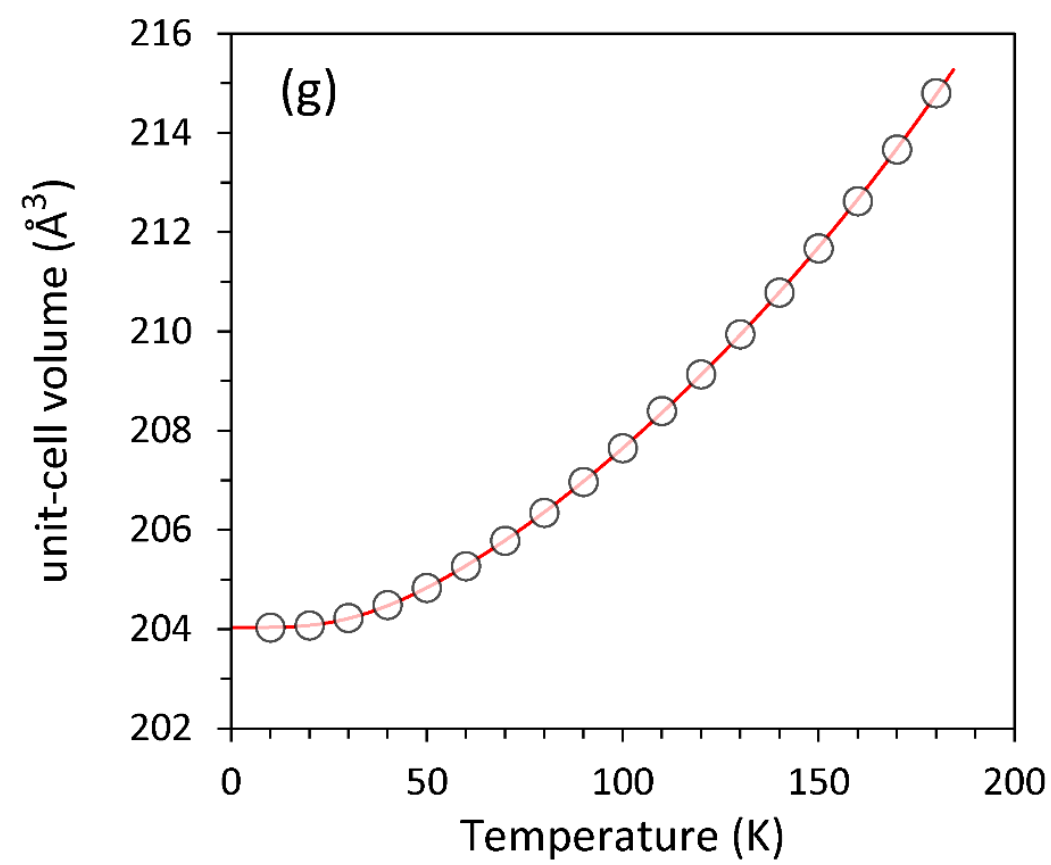




\section{Electronic Supplementary Information}

\section{Figure S3}

Unit-cell parameters of ethanol hemi-ammoniate between 70 and $175 \mathrm{~K}$ : (a) $a$-axis; (b) $b$-axis; (c) $c$-axis; (d) angle $\alpha$; (e) angle $\beta$; (f) angle $\gamma$; (g) unit-cell volume (overleaf). Open circles represent the observations and the solid lines are polynomial fits (see main text)
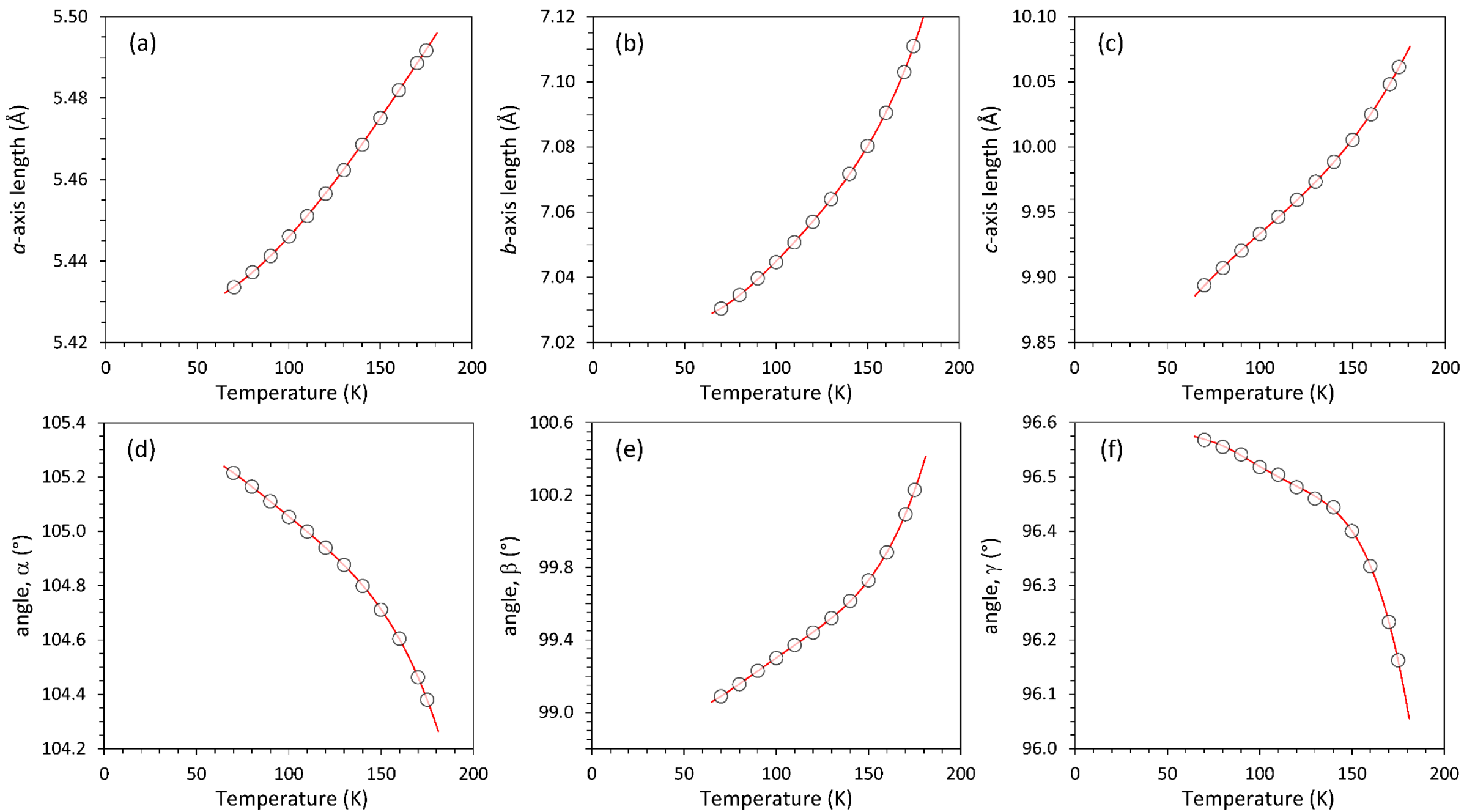
Electronic Supplementary Information

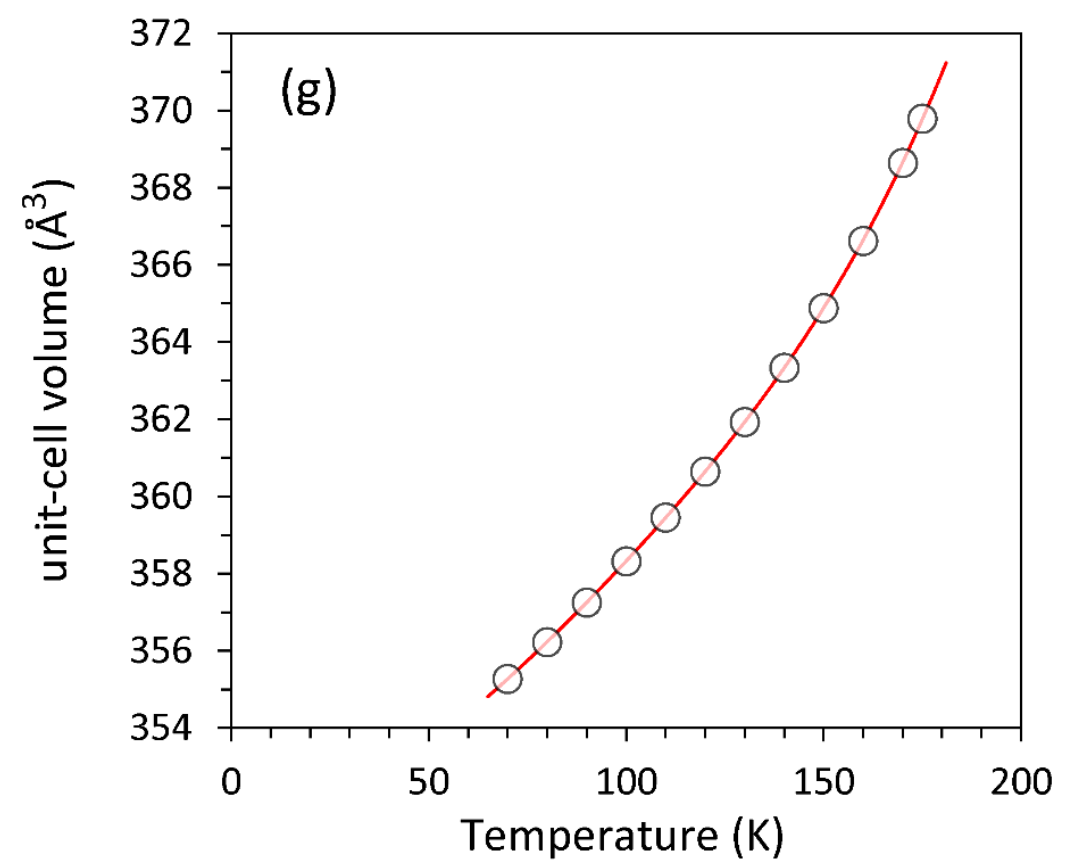




\section{Electronic Supplementary Information}

\section{Figure S4}

Unit-cell parameters of ethanol mono-ammoniate obtained from DFT calculations over the range of pressures 0 - 25 GPa: (a) $a$-axis; (b) $b$-axis; (c) $c$-axis; (d) angle $\alpha$; (e) angle $\beta$; (f) angle $\gamma$; (g) unit-cell volume (overleaf). Open circles correspond with the molecular co-crystal and filled circles correspond to the ionic crystal.
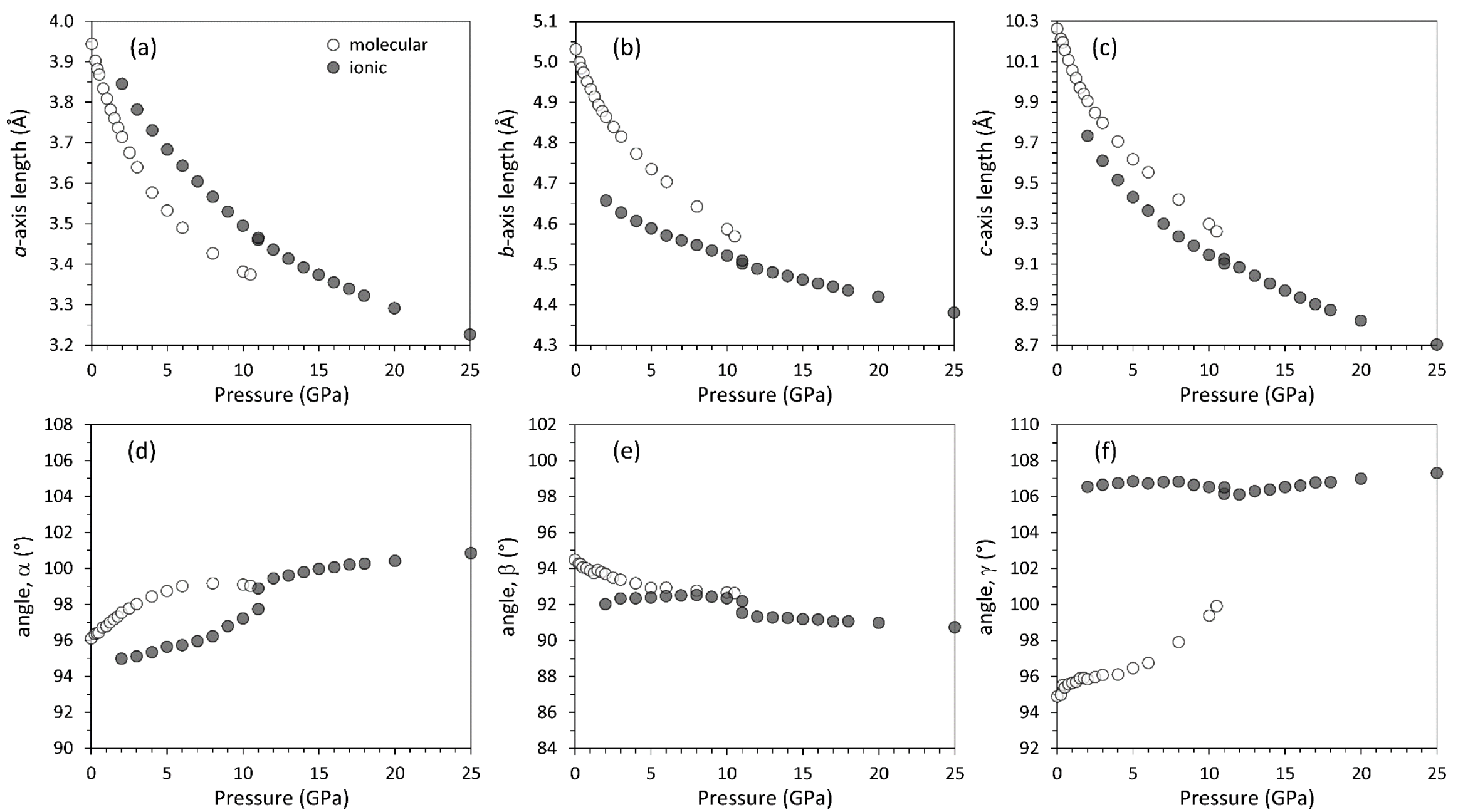
Electronic Supplementary Information

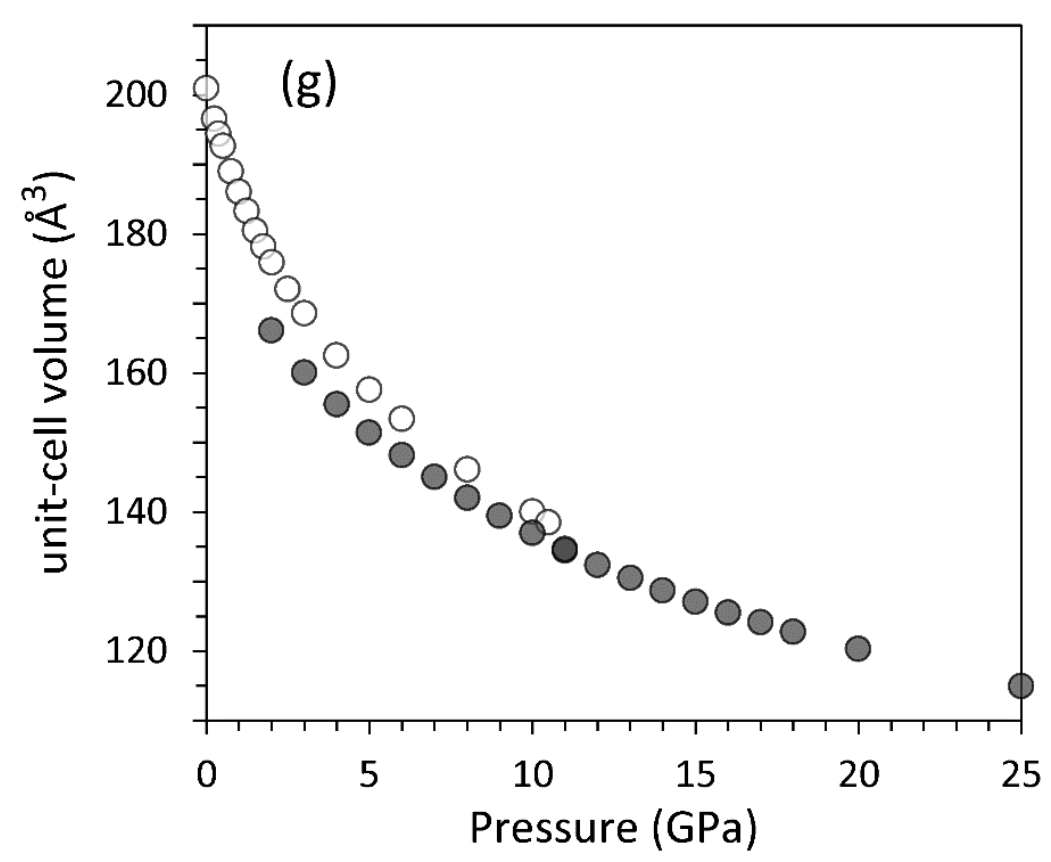




\section{Electronic Supplementary Information}

\section{Figure S5}

Unit-cell parameters of ethanol hemi-ammoniate obtained from DFT calculations over the range of pressures 0 - 20 GPa: (a) $a$-axis; (b) $b$-axis; (c) $c$-axis; (d) angle $\alpha$; (e) angle $\beta$; (f) angle $\gamma$; (g) unit-cell volume (overleaf). Open circles correspond with the molecular co-crystal and filled circles correspond to the ionic co-crystal.
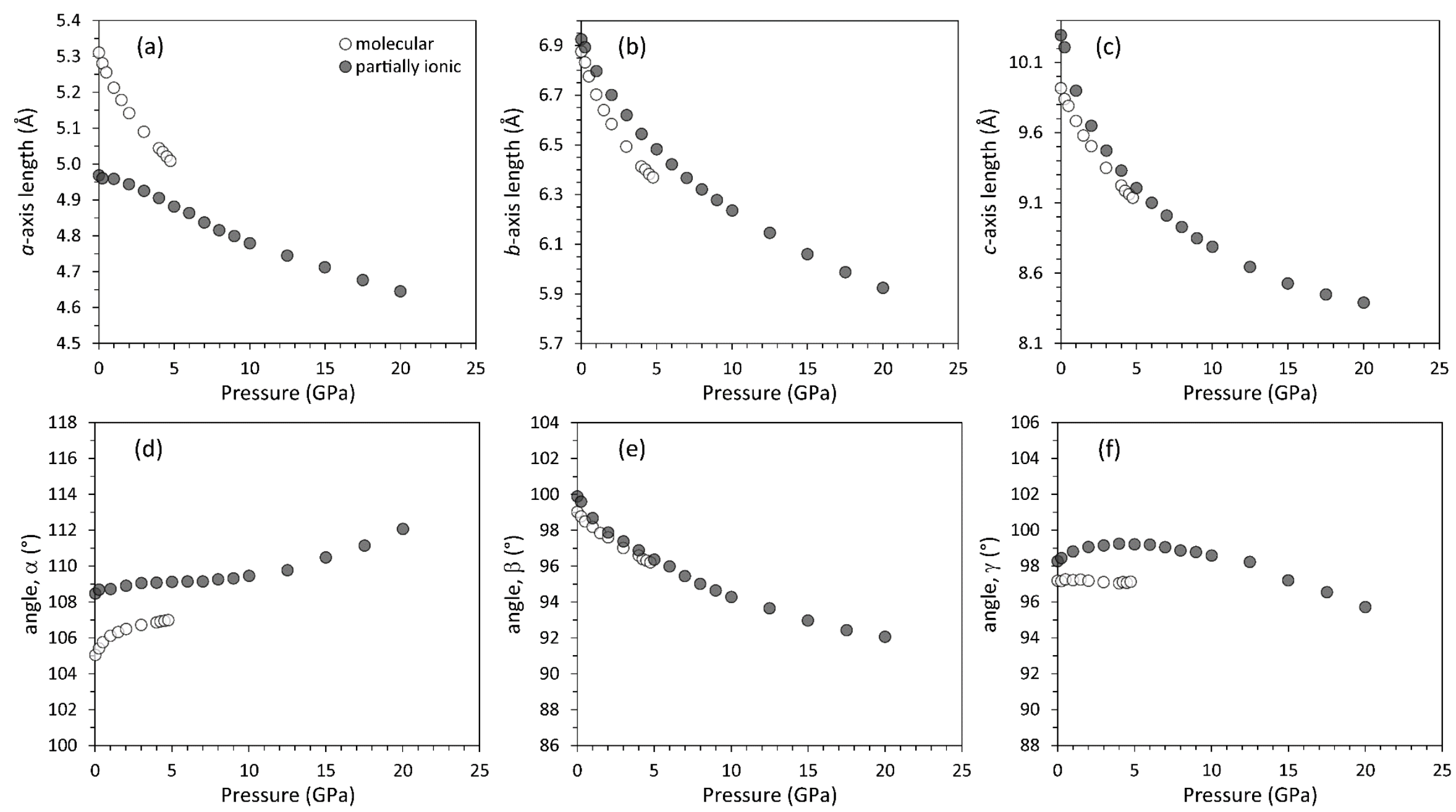
Electronic Supplementary Information

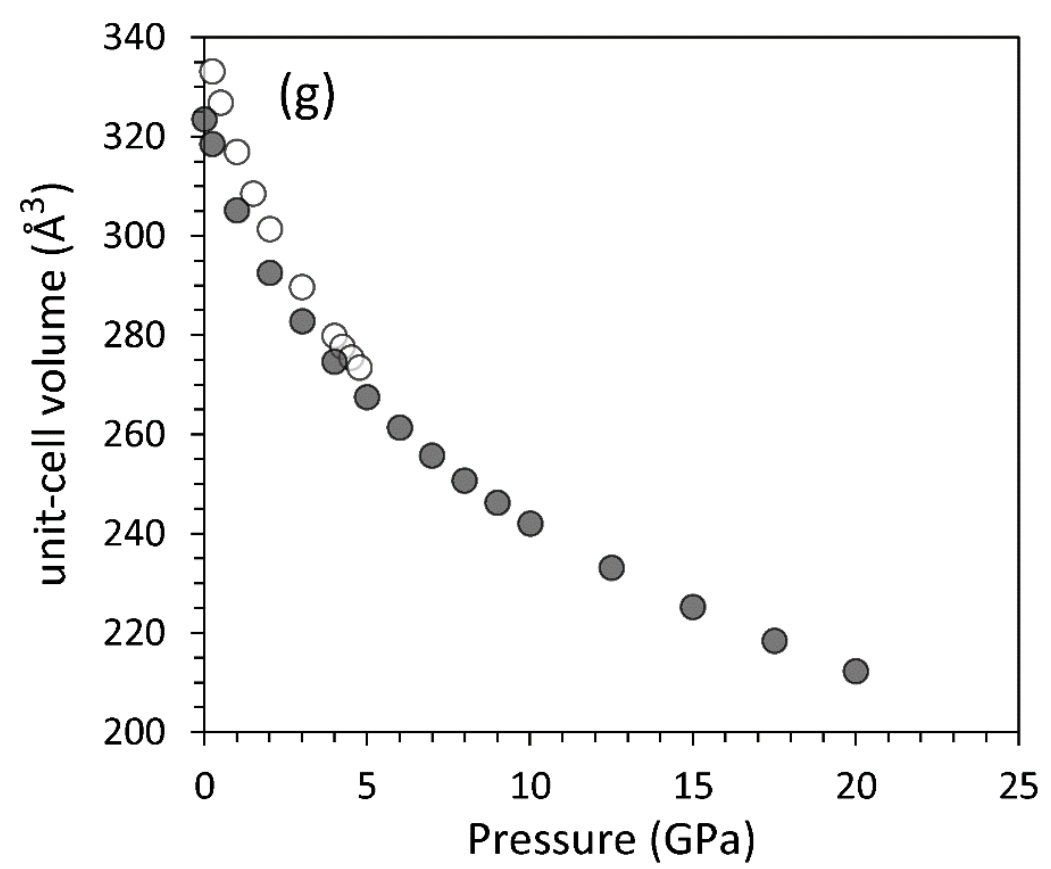




\section{Electronic Supplementary Information}

\section{Table S1}

Refined unit-cell parameters of ethanol mono-ammoniate. These data are plotted in Fig. S2.

\begin{tabular}{|c|ccccccc|}
\hline $\mathrm{T}(\mathrm{K})$ & $a(\AA)$ & $b(\AA)$ & $c(\AA)$ & $\alpha\left(^{\circ}\right)$ & $\beta\left(^{\circ}\right)$ & $\gamma\left({ }^{\circ}\right)$ & $\mathrm{V}\left(\AA^{3}\right)$ \\
\hline 180 & $4.06831(2)$ & $5.17400(2)$ & $10.38296(4)$ & $94.8905(4)$ & $94.9238(4)$ & $97.6082(3)$ & $214.796(1)$ \\
170 & $4.05297(3)$ & $5.16932(3)$ & $10.37842(6)$ & $94.916(1)$ & $94.867(1)$ & $97.696(1)$ & $213.664(2)$ \\
160 & $4.03938(3)$ & $5.16469(3)$ & $10.37348(6)$ & $94.942(1)$ & $94.816(1)$ & $97.769(1)$ & $212.626(2)$ \\
150 & $4.02744(3)$ & $5.16011(3)$ & $10.36812(7)$ & $94.965(1)$ & $94.769(1)$ & $97.828(1)$ & $211.676(2)$ \\
140 & $4.01635(4)$ & $5.15569(4)$ & $10.36266(9)$ & $94.991(1)$ & $94.725(1)$ & $97.879(1)$ & $210.780(2)$ \\
130 & $4.00592(5)$ & $5.15160(5)$ & $10.35727(11)$ & $95.015(1)$ & $94.682(1)$ & $97.923(1)$ & $209.938(3)$ \\
120 & $3.99609(6)$ & $5.14768(6)$ & $10.35179(13)$ & $95.034(1)$ & $94.645(1)$ & $97.965(1)$ & $209.137(3)$ \\
110 & $3.98663(7)$ & $5.14565(8)$ & $10.34752(14)$ & $95.080(1)$ & $94.615(1)$ & $97.988(1)$ & $208.396(4)$ \\
100 & $3.97561(6)$ & $5.14271(6)$ & $10.34291(13)$ & $95.103(1)$ & $94.584(1)$ & $98.029(1)$ & $207.647(4)$ \\
90 & $3.96668(6)$ & $5.13982(6)$ & $10.33861(13)$ & $95.127(1)$ & $94.549(1)$ & $98.055(1)$ & $206.966(4)$ \\
80 & $3.95831(7)$ & $5.13759(7)$ & $10.33426(14)$ & $95.151(1)$ & $94.524(1)$ & $98.077(2)$ & $206.340(4)$ \\
70 & $3.95055(7)$ & $5.13551(7)$ & $10.33077(15)$ & $95.185(1)$ & $94.497(1)$ & $98.084(2)$ & $205.776(4)$ \\
60 & $3.94358(7)$ & $5.13377(7)$ & $10.32737(15)$ & $95.209(1)$ & $94.475(1)$ & $98.096(2)$ & $205.267(4)$ \\
50 & $3.93749(7)$ & $5.13245(7)$ & $10.32426(16)$ & $95.235(1)$ & $94.454(2)$ & $98.097(2)$ & $204.833(4)$ \\
40 & $3.93245(7)$ & $5.13146(7)$ & $10.32203(16)$ & $95.259(1)$ & $94.442(1)$ & $98.094(2)$ & $204.484(4)$ \\
30 & $3.92857(7)$ & $5.13100(7)$ & $10.32021(17)$ & $95.279(1)$ & $94.432(1)$ & $98.083(2)$ & $204.228(4)$ \\
20 & $3.92649(7)$ & $5.13043(7)$ & $10.31895(16)$ & $95.291(1)$ & $94.428(1)$ & $98.076(2)$ & $204.074(4)$ \\
10 & $3.92592(5)$ & $5.13030(5)$ & $10.31853(11)$ & $95.296(1)$ & $94.425(1)$ & $98.070(1)$ & $204.033(3)$ \\
\hline
\end{tabular}

\section{Table S2}

Refined unit-cell parameters of ethanol hemi-ammoniate. These data are plotted in Fig. S3.

\begin{tabular}{|c|ccccccc|}
\hline $\mathrm{T}(\mathrm{K})$ & $a(\AA)$ & $b(\AA)$ & $c(\AA)$ & $\alpha\left(^{\circ}\right)$ & $\beta\left(^{\circ}\right)$ & $\gamma\left({ }^{\circ}\right)$ & $\mathrm{V}\left(\AA^{3}\right)$ \\
\hline 175 & $5.49172(1)$ & $7.11096(2)$ & $10.06131(2)$ & $104.3802(2)$ & $100.2283(2)$ & $96.1623(2)$ & $369.793(1)$ \\
170 & $5.48859(3)$ & $7.10297(5)$ & $10.04815(6)$ & $104.4630(5)$ & $100.0948(4)$ & $96.2331(6)$ & $368.644(3)$ \\
160 & $5.48197(3)$ & $7.09051(5)$ & $10.02501(6)$ & $104.6053(5)$ & $99.8834(5)$ & $96.3358(6)$ & $366.628(3)$ \\
150 & $5.47517(4)$ & $7.08034(6)$ & $10.00558(8)$ & $104.712(1)$ & $99.729(1)$ & $96.400(1)$ & $364.882(3)$ \\
140 & $5.46864(5)$ & $7.07179(9)$ & $9.98880(11)$ & $104.799(1)$ & $99.616(1)$ & $96.444(1)$ & $363.342(5)$ \\
130 & $5.46235(5)$ & $7.06404(8)$ & $9.97347(10)$ & $104.877(1)$ & $99.521(1)$ & $96.460(1)$ & $361.933(4)$ \\
120 & $5.45655(6)$ & $7.05704(10)$ & $9.95943(13)$ & $104.940(1)$ & $99.441(1)$ & $96.481(1)$ & $360.647(5)$ \\
110 & $5.45111(6)$ & $7.05076(10)$ & $9.94649(14)$ & $104.999(1)$ & $99.372(1)$ & $96.504(1)$ & $359.457(6)$ \\
100 & $5.44610(7)$ & $7.04468(11)$ & $9.93329(15)$ & $105.053(1)$ & $99.300(1)$ & $96.518(1)$ & $358.320(6)$ \\
90 & $5.44128(7)$ & $7.03970(12)$ & $9.92058(17)$ & $105.111(1)$ & $99.230(1)$ & $96.541(2)$ & $357.250(7)$ \\
80 & $5.43729(8)$ & $7.03461(13)$ & $9.90727(18)$ & $105.165(1)$ & $99.156(1)$ & $96.555(2)$ & $356.230(7)$ \\
70 & $5.43361(13)$ & $7.03045(20)$ & $9.89395(26)$ & $105.215(2)$ & $99.088(2)$ & $96.568(3)$ & $355.28(1)$ \\
\hline
\end{tabular}




\section{Electronic Supplementary Information}

\section{Table S3}

Parameters obtained from fitting a $2^{\text {nd }}$ order Debye model to the unit-cell edges $(a, b, c)$ and the unit-cell volume of ethanol mono-ammoniate, and fitting of modified polynomials to the inter-axial angles $(\alpha, \beta, \gamma)$. The polynomial functions are of the form, $a(T)=a_{0}+a_{2} T^{2}+a_{3} T^{3}$ $+\mathrm{a}_{4} T^{4}+\mathrm{a}_{5} T^{5}+\mathrm{a}_{6} T^{6}$. The results are plotted as solid lines in Figure $\mathrm{S} 2$.

\begin{tabular}{|l|cccc|}
\hline Debye & $a$-axis & $b$-axis & $c$-axis & Volume \\
\hline$V_{0}\left(\AA, \AA_{3}\right)$ & $3.9257(16)$ & $5.1305(6)$ & $10.3189(8)$ & $204.034(13)$ \\
$\theta_{\mathrm{D}}(\mathrm{K})$ & $149(11)$ & $236(21)$ & $186(13)$ & $165(4)$ \\
$K_{0} / \gamma(\mathrm{GPa})$ & $29(1)$ & $48(5)$ & $6.7(5)$ & $17.2(3)$ \\
$K_{0}^{\prime}$ & $7.8(8)$ & $37(6)$ & $9.9(5)$ & $14.9(6)$ \\
& & & & \\
\hline Polynomial & $\alpha$ & $\beta$ & $\gamma$ & \\
\hline & & & & \\
$\mathrm{a}_{0}$ & $95.294(3)$ & $94.425(1)$ & $98.063(3)$ & \\
$\mathrm{a}_{2}$ & 0 & 0 & $5.3(5) \times 10^{-5}$ & \\
$\mathrm{a}_{3}$ & $-9.3(8) \times 10^{-7}$ & $3.7(1) \times 10^{-7}$ & $-1.1(1) \times 10^{-6}$ & \\
$\mathrm{a}_{4}$ & $1.3(2) \times 10^{-9}$ & $-2.9(1) \times 10^{-9}$ & $6.4(8) \times 10^{-9}$ & \\
$\mathrm{a}_{5}$ & $-6.6(12) \times 10^{-11}$ & $7.1(5) \times 10^{-12}$ & $-1.5(2) \times 10^{-11}$ & \\
$\mathrm{a}_{6}$ & $1.2(3) \times 10^{-14}$ & 0 & 0 & \\
& & & & \\
\hline
\end{tabular}




\section{Electronic Supplementary Information}

\section{Table S4}

Refined unit-cell parameters of deutero-ammonia. These data are plotted in the main text, Figure 12.

\begin{tabular}{|c|c|}
\hline $\mathrm{T}(\mathrm{K})$ & $a(\AA)$ \\
\hline 180 & $5.13559(2)$ \\
170 & $5.12765(3)$ \\
160 & $5.11984(3)$ \\
150 & $5.11272(3)$ \\
140 & $5.10591(3)$ \\
130 & $5.0997(2)$ \\
120 & $5.0936(2)$ \\
110 & $5.0881(2)$ \\
100 & $5.0829(2)$ \\
90 & $5.0781(2)$ \\
80 & $5.0739(2)$ \\
70 & $5.0699(2)$ \\
60 & $5.0667(2)$ \\
50 & $5.0639(2)$ \\
40 & $5.0617(2)$ \\
30 & $5.0603(2)$ \\
20 & $5.0596(2)$ \\
10 & $5.0593(2)$ \\
\hline
\end{tabular}




\section{Electronic Supplementary Information}

\section{Table S5}

Comparison of the experimental low-temperature unit-cell parameters of ethanol mono- and hemi-ammoniate with those found at zero pressure and temperature by DFT calculation.

\begin{tabular}{|l|ccc|ccc|}
\hline & \multicolumn{3}{|c|}{ Ethanol mono-ammoniate } & \multicolumn{3}{c|}{ Ethanol hemi-ammoniate } \\
& Expt. 10 K & DFT 0 K & $\Delta(\%)$ & Expt. 70 K & DFT 0 K & $\Delta(\%)$ \\
\hline & & & & & & \\
$b(\AA)$ & $3.92592(5)$ & 3.944321 & 0.469 & $5.4336(1)$ & 5.310610 & -2.264 \\
$c(\AA)$ & $5.13030(5)$ & 5.031089 & -1.934 & $7.0305(2)$ & 6.875528 & -2.204 \\
$\alpha(\AA)$ & $10.3185(1)$ & 10.26296 & -0.539 & $9.8940(3)$ & 9.918167 & 0.248 \\
$\alpha\left(^{\circ}\right)$ & $95.296(1)$ & 96.10376 & 0.848 & $105.215(2)$ & 105.04375 & -0.163 \\
$\beta\left(^{\circ}\right)$ & $94.425(1)$ & 94.49019 & 0.069 & $99.088(2)$ & 99.02780 & -0.061 \\
$\gamma\left({ }^{\circ}\right)$ & $98.070(1)$ & 94.87766 & -3.255 & $96.568(3)$ & 97.17857 & 0.632 \\
$\mathrm{~V}\left(\AA^{3}\right)$ & $204.033(3)$ & 200.98713 & -1.493 & $355.28(1)$ & 340.14873 & -4.258 \\
$b / a$ & $1.30678(2)$ & 1.27553 & -2.391 & $1.29388(5)$ & 1.29468 & 0.061 \\
$c / a$ & $2.62831(5)$ & 2.60196 & -1.002 & $1.82088(6)$ & 1.86761 & 2.566 \\
\hline
\end{tabular}

\section{Table S6}

Parameters obtained from fitting of a $4^{\text {th }}$ order logarithmic equation of state to the $E(V)$ curves of ethanol mono- and hemi-ammoniates in both their molecular and ionic forms. See main text for details of the fitted equations and Figure 14 for a plot of the curves. Since the ionic mono-ammoniate could not be relaxed below $2 \mathrm{GPa}$, the shape of the $E(V)$ curve around $V_{0}$ is not constrained and consequently the uncertainty in the fit parameters is poor. Furthermore, the value of $K_{0}{ }^{\prime \prime}$ had to be fixed and a choice was made to use the same value found in the molecular phase.

\begin{tabular}{|c|c|c|c|c|}
\hline & \multicolumn{2}{|c|}{ Ethanol mono-ammoniate } & \multicolumn{2}{|c|}{ Ethanol hemi-ammoniate } \\
\hline & $\begin{array}{c}\text { Molecular } \\
\mathrm{C}_{2} \mathrm{H}_{5} \mathrm{OH} \cdot \mathrm{NH}_{3} \\
\end{array}$ & $\begin{array}{c}\text { Ionic } \\
\mathrm{C}_{2} \mathrm{H}_{5} \mathrm{O}^{-} \cdot \mathrm{NH}_{4}^{+} \\
\end{array}$ & $\begin{array}{c}\text { Molecular } \\
2\left(\mathrm{C}_{2} \mathrm{H}_{5} \mathrm{OH}\right) \cdot \mathrm{NH}_{3}\end{array}$ & $\begin{array}{c}\text { Partially ionic } \\
\mathrm{C}_{2} \mathrm{H}_{5} \mathrm{OH} \cdot \mathrm{C}_{2} \mathrm{H}_{5} \mathrm{O}^{-} \cdot \mathrm{NH}_{4}^{+}\end{array}$ \\
\hline$V_{0}\left(\AA^{3}\right)$ & $197.98(16)$ & $181.8(14)$ & $334.90(22)$ & $319.86(10)$ \\
\hline$K_{0}(\mathrm{GPa})$ & $10.8(1)$ & $15.4(12)$ & $11.9(2)$ & $14.00(6)$ \\
\hline & $5.9(4)$ & $6.1(1)$ & $7.6(2)$ & $8.8(1)$ \\
\hline$K_{0}^{\prime \prime}\left(\mathrm{GPa}^{-1}\right)$ & $-1.1(7)$ & $-1.1 *$ & $-3.6(7)$ & $-4.3(2)$ \\
\hline$E_{0}(\mathrm{eV})$ & $-2328.5126(6)$ & $-2328.24(1)$ & $-4016.5736(7)$ & $-4016.6033(7)$ \\
\hline
\end{tabular}

*Fixed at same value as in molecular EMA. 